\title{
برنامج إرشادي لتنمية الكفاءة الإدارية لربة الأسرة
}

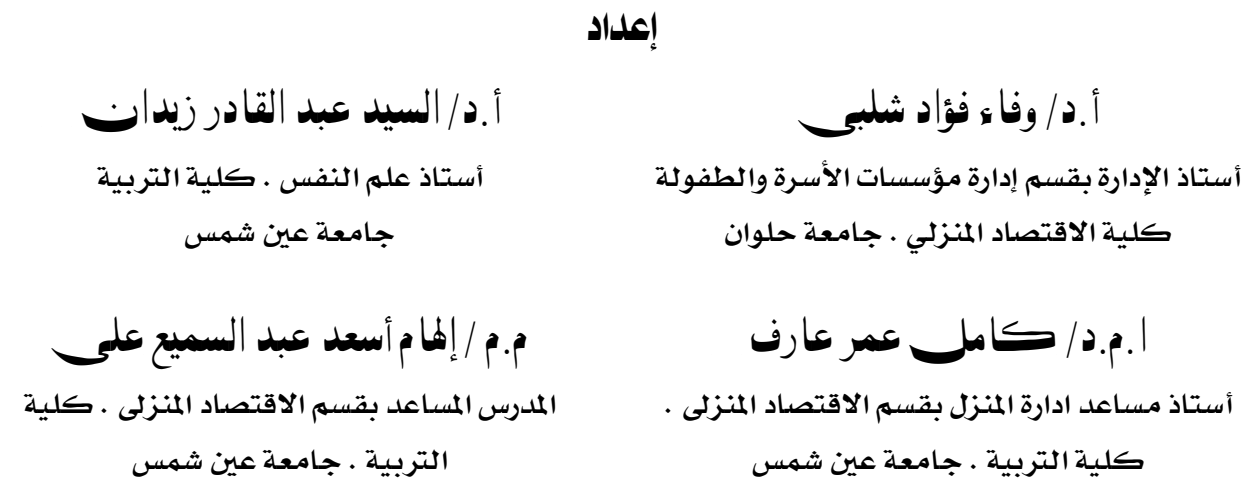

مجلة بحوث التربية النوعية - جامعة المنصورة

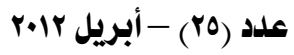




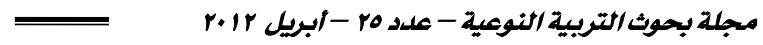

\section{برناهم إرشادي لتنمية الكفاءة الإدارية لربة الأسرة}

إعداد

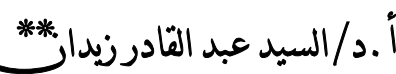

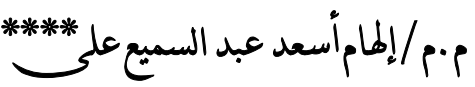

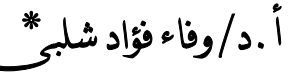

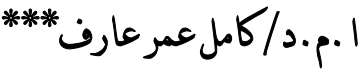

\section{: الاll|}

أجري هذا البحث بهاف إعداد وتطبيق وتوضيح حجم تاثير برنـامـج إرثـادي لتنميـة الكفـاءة

الإدارية لربية الأسرة

واشتهمل البحث علي عينة من مجموعتان عينـة الدراسـة الاسـاسية وقوا مها ..بـ ريـة اسـرة مـن

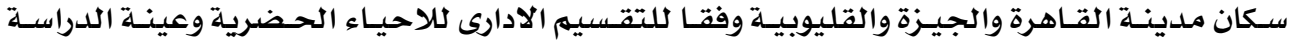

التجريبية وقوامها ( .7) رية اسـرة.

$$
\text { وكانت أهم النتائج : }
$$

وجود فروقا ذات دلالة احصائية بين المراه العاملة وغير العاملـة فى محساور مقيـاس الكفـاءة الادرايـة

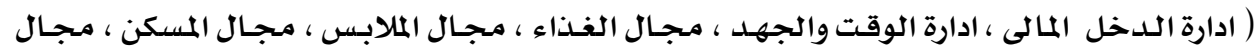

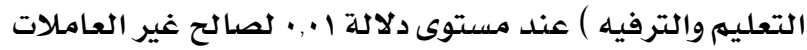

- وجود علاقة ارتباطية موجبة بـين مـدة الحيـاة الزوجيـة و كـلا مـن محساور مقيـاس الكفـاءة الاداريـة

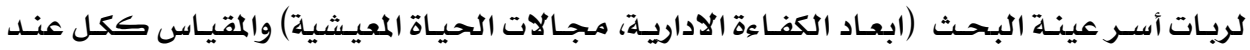

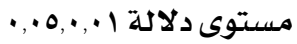

- وجود فروق دالـة احصائيا " بـين متوسططات درجـات التطبيق القبلى والبعـدى فـى مستوى الكفـاءة

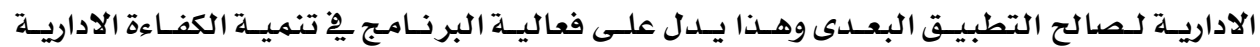
لرية المنزل 


\section{Summary \\ INDICATIVE PROGRAMME FOR THE DEVELOPMENT OF MANAGERIAL EFFICIENT TO THE HOUSEWIFE}

This research was conducted to prepare, implement and clarify the magnitude of the effect Indicative Programme for the Development of managerial efficient to the Housewife

The research involved a sample of two groups the study sample and core of (300) Housewife from the city of Cairo, Giza, and in accordance with the administrative division of districts and urban sample of the pilot study and consisted of (60) Housewife .The most important results: - The existence of statistically significant differences between working women and non-hubs in the scale of managerial efficient at the level of significance(0.01)for-non-working The presence of a positive correlation between the duration of married life and both of the axes scale managerial efficient of the housewife of the research sample and scale as a whole at the level of significance $(0.05 \cdot 0,01)$ - The presence of statistically significant differences "between the mean scores of pre and post application in the level of managerial efficient for the benefit of the post and this shows the effectiveness of the program in the development of managerial efficient for the housewife. 


\section{برناهة إرشادي لتنسية الكفاءة الإدارية لربة الأسرة}

إعداد

\author{
أ .د السيد عبد القادرزيداز.

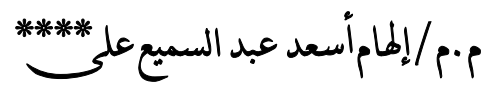

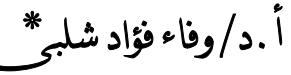

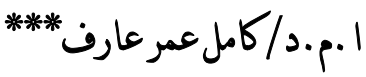

همدمة ومشكلة البحث:-

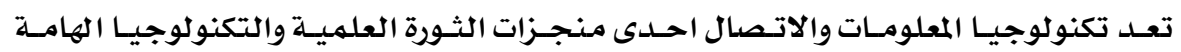

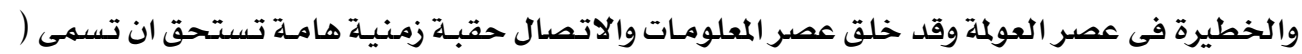

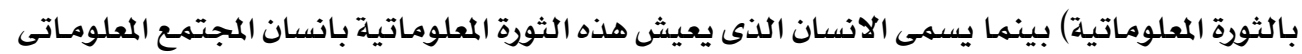

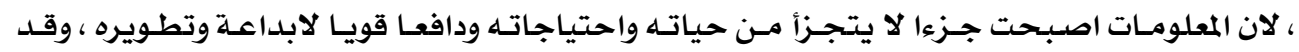

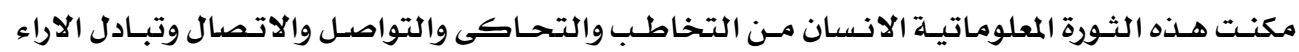

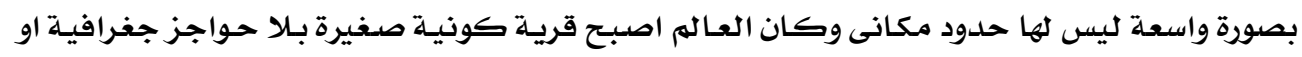

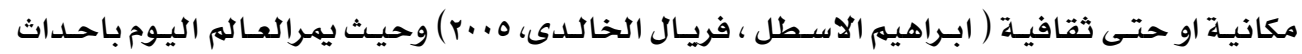

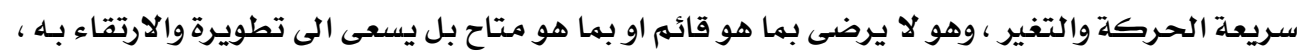

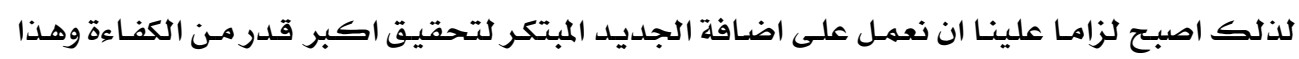

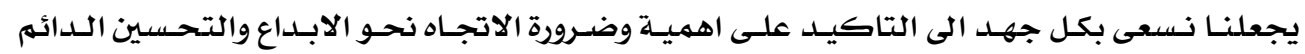

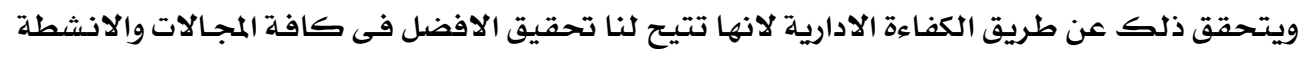

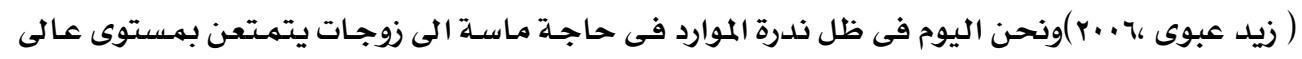

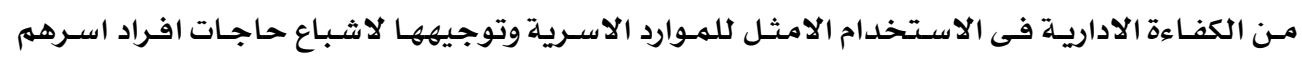

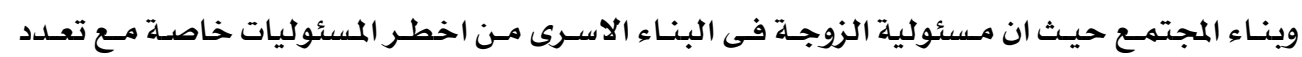

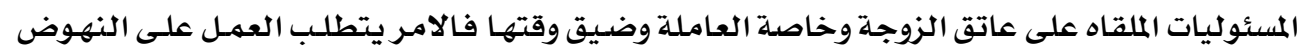

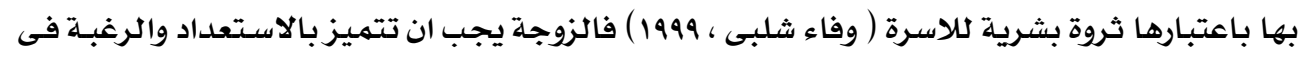

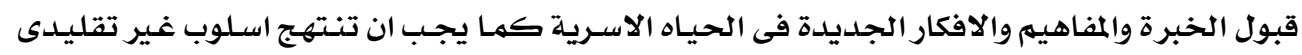

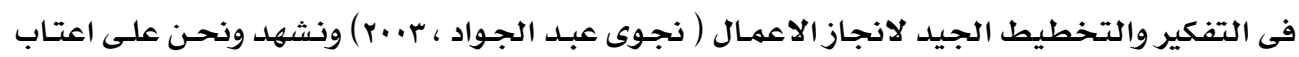

أستاذ الإدارة بقسهم إدارة مؤسسات الأسرة والطفولة كلية الاقتصاد المنزلي · جامعة حلوان

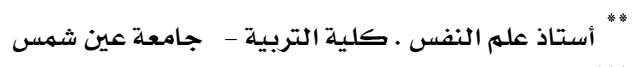

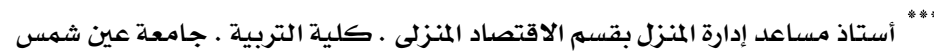

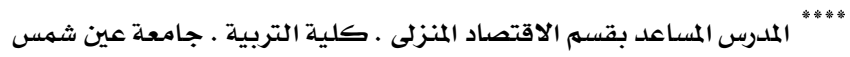




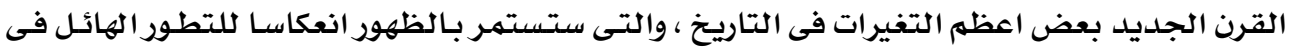

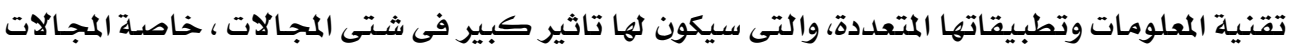

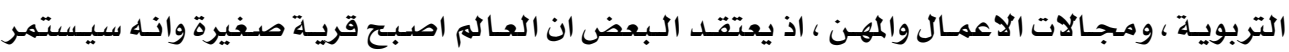

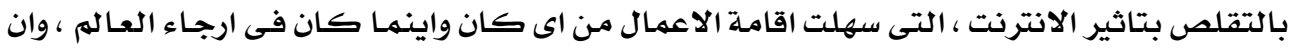

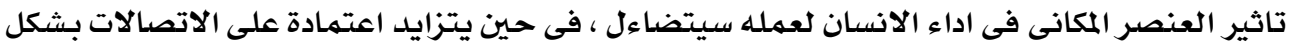

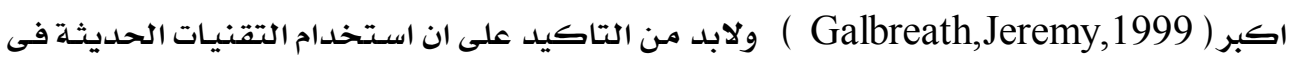

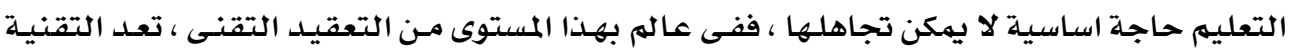

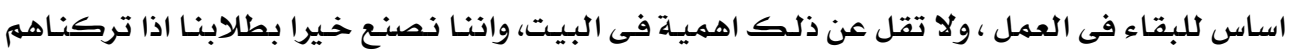

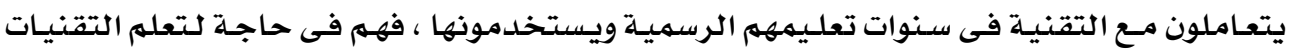

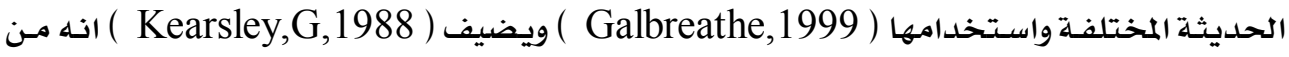

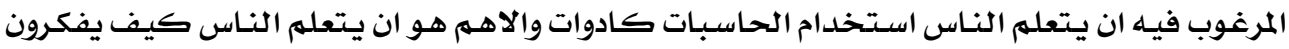
وكيف يحلون المشكلات ويتخذون القرارات باستخدام النسات الكاتك الادوات.

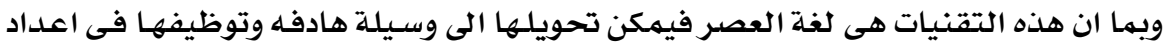

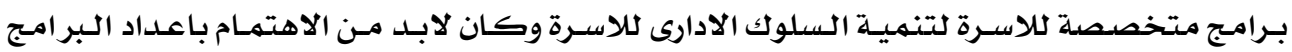

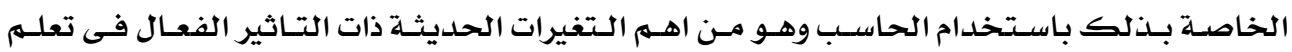

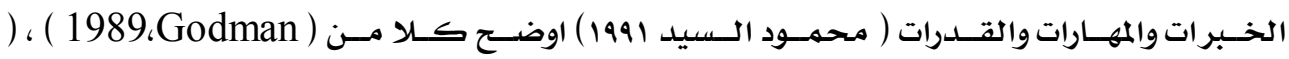

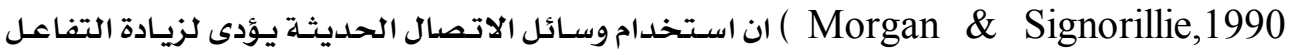

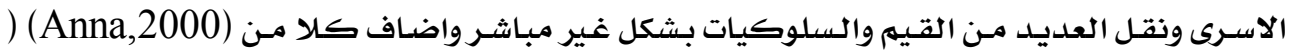

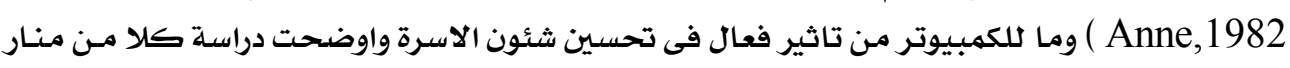

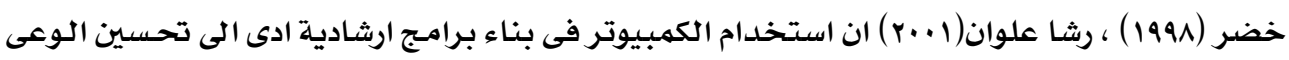
بالممارسات الادارية والمهارات.

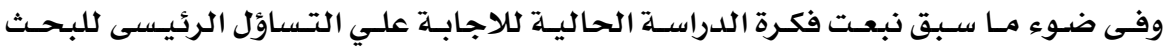

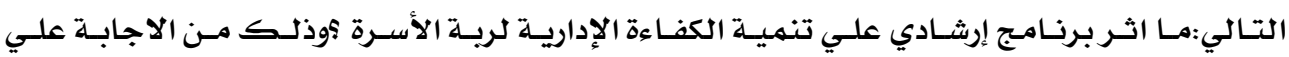

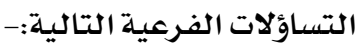

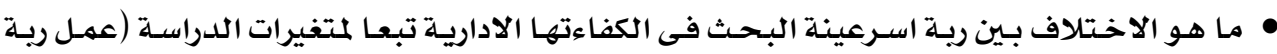

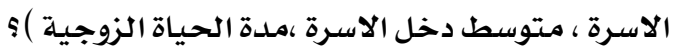

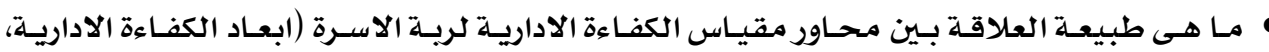

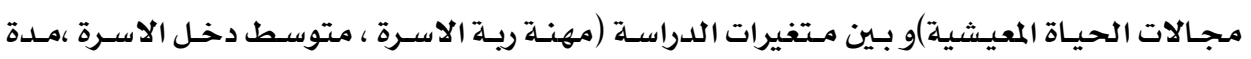

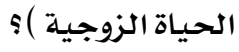

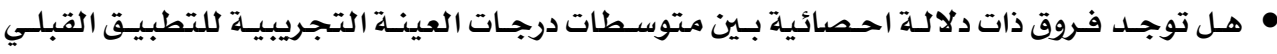

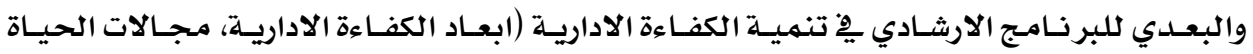

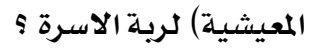




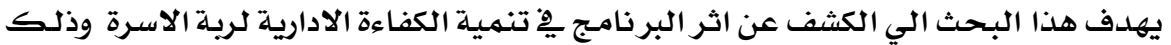
من خلال : توضـيح الفـروق بـين ريـة اسـرعينـة البـحث في الكفاءتهـا الاداريـة تبعـا لمتغيرات الدراسـة (عمـل ربـة الاسـرة ، متوسط دخل الاسرة ،مدة الحياة الزوجية ). الكشف عن طبيعة العلاقة بين محاور مقياس الكفـاءة الاداريـة لربـة الاسـرة (ابعـاد الكفـاءة الاداريـة،

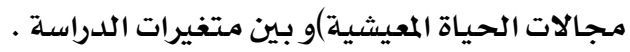
• التعرف علي فاعلية البرنامـج الارشادي المعد يخ تنمية الكفاءة الاداريـة لربة الاسـرة.

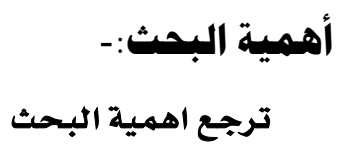

•• رفع مستوى الاسرة اداريا واقتصاديا ، وتدعيم القيم والتقاليد المرتبطة بالحياة الاسـرية التى تلائمم

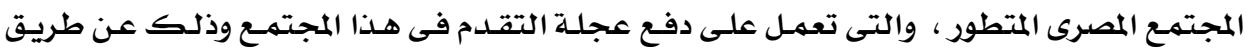
تنهيـة شخصيات افراد الاسـرة بصورة متكاملة متوازنة واعدادهم كافراد منتجـين يعملـون لخيرهـم وخير اسرهم وخير امتهم.

استخدام التكنولوجيا الحديثة واسـاليبها المبتكرة بها يعهـل على تضييق الفجـوه الحضارية بينها وبين العالم المتقدم.

• توضيح اهميـة الكفاءة الاداريـة لريسة الاسـرة فى تنهيـة وتحسـين وتطوير المهارات الاداريـة .

\section{فروض البمث:}

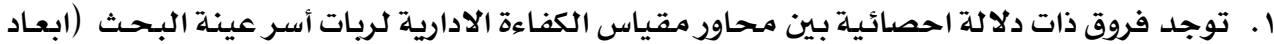

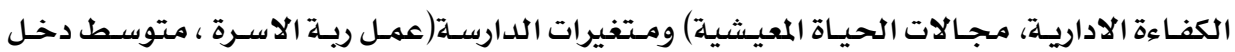
الاسرة ،مدة الحياة الزوجيـة ).

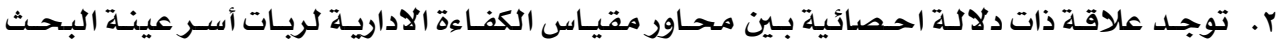

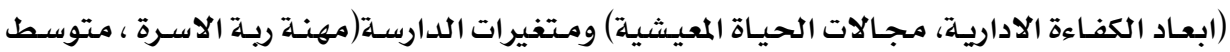
دخل الاسـرة ،مدة الحيـاة الزوجيـة ). r. توجد فروق ذات دلاللة احصائية بين متتوسطات درجات العينـة التجريبية للتطبيق القبلي والبعـدي

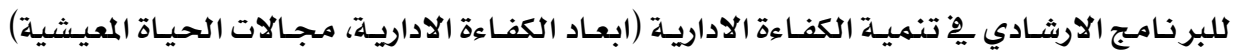
كربة الاسرة لصالح التطبيق البعدي. 


\section{برئامج إرشادي لتنصية /لكفاءة الإدرارية لرية الأسرة \\ هصطالحات البحث:- \\ Managerial efficient : الكفاءة الادارية}

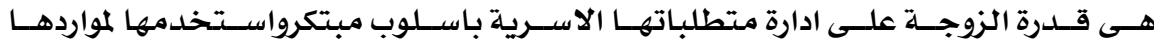

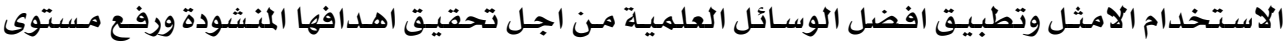

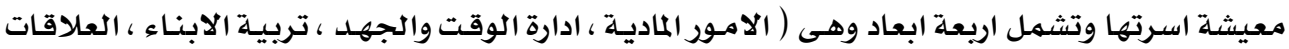

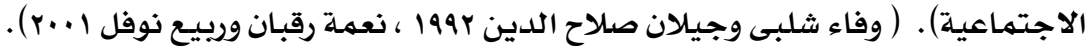

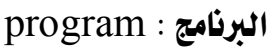

هو إطار يتضمن مجموعة من الخبر ات تقدم لمجموعة مـن الدارسـين لتحقيق اهـداف خاصـة

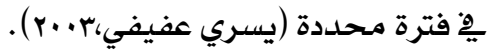
هن:هن البمث: يتبـع هذا البحث المنهج الوصفى ، والمنهج التجريبى

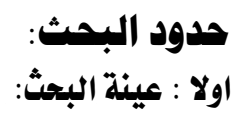

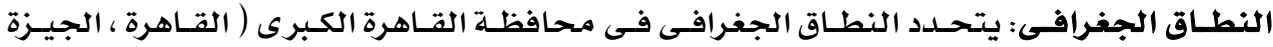

$$
\text { والقليوبية) }
$$

النطاق البشرى : تتكون عينة البحث من مجموعتان - عينـة الدراسـة الاسـاسية وقوامها ..ب رية اسـرة مـن سـكان مدينـة القـاهرة والجيزة والقليوبيـة وفقـا

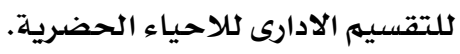

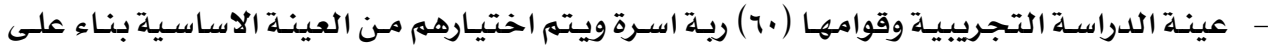

$$
\text { ثانيا:ـ أدوات البحث مقياس الكفاءة الادارية وذلك لتطبيق البرنامج المعد عليهم. }
$$

ا- استمارة البيانات العامة لاسر عينة البحث والابناء وتشتمل على اعداد الباحثة)

(أ) بيانات عن اسـر الابنـاء مـن حيـث مستوى تعليه الوالـدين ، متوسـط الـدخل ، حجـم الاسـرة ،

مكان الاقامة) - مالمة

(ب) بيانات عن الابناء من حيث ( النوع ، السن ، الصف الدراسى ، نوعية المدارس)

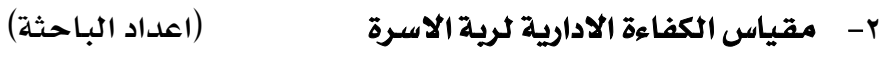

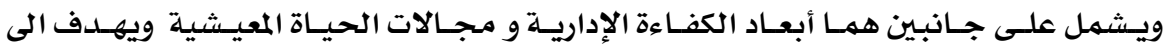

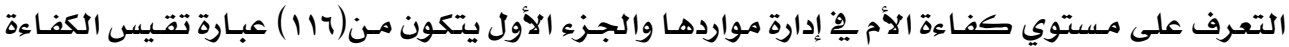




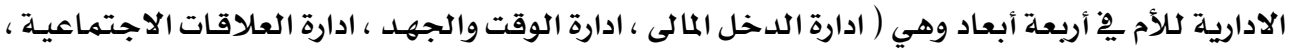

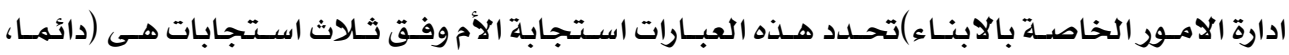

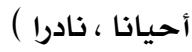

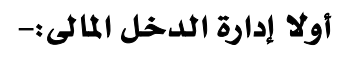

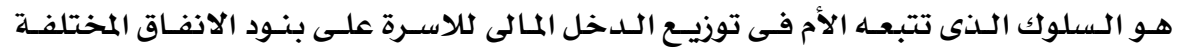
ويتكون من(ro)عبارة تقيس كفاءة الام يِّ ادارة الامور المالية.

\section{ثانيا ادارة الوقت والجهد:-}

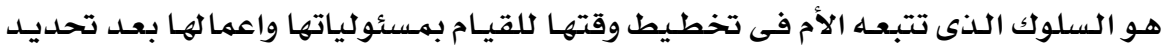

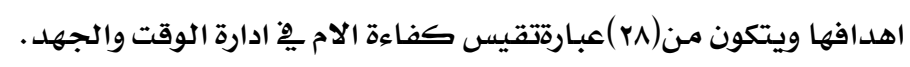
ثالثا ادارة العلاقات الاجتماعية:-

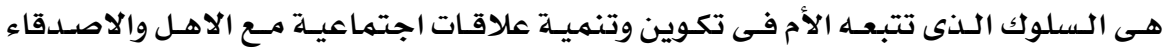
والزملاء ويتكون من(ro) عبارةتقيس كفاءة الام ِِّ تكوين العلاقات الاجتماعية.

\section{رابعا ادارة الامور الخاصة بالابناء:-}

هى السلوك الذى تتبعه الأم فى تربيـة الابنـاءوالتى تسفر عن اكتسابهمه اسـاليب سـلوكية

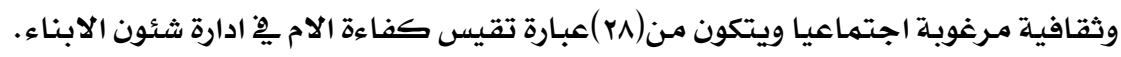

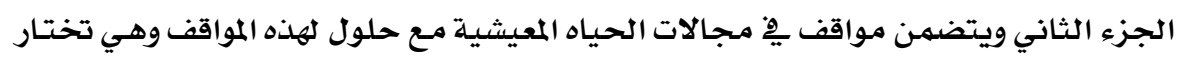

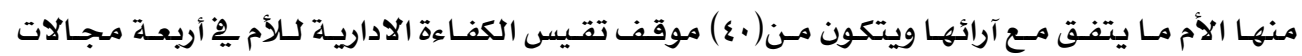

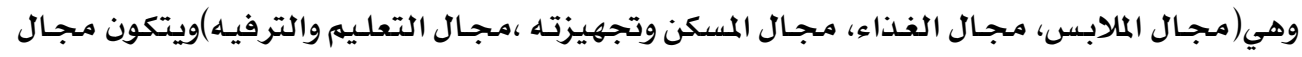

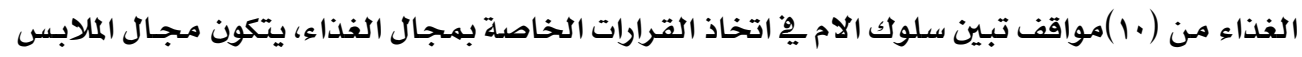

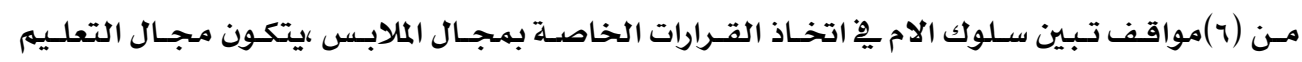

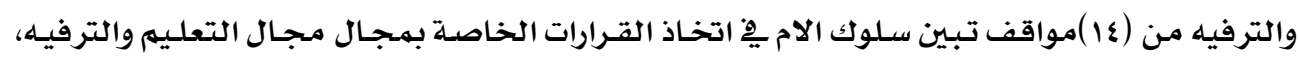

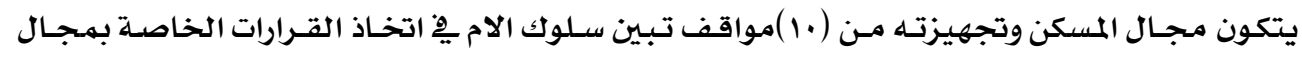

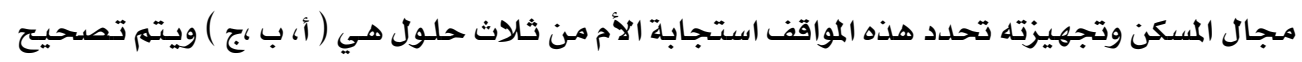

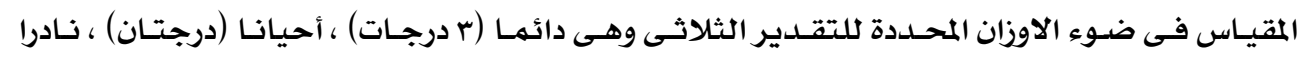

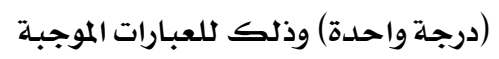

$$
\text { صدق المقياس :- واستخدمت الباحثة لتقيس معامل الصدل: }
$$

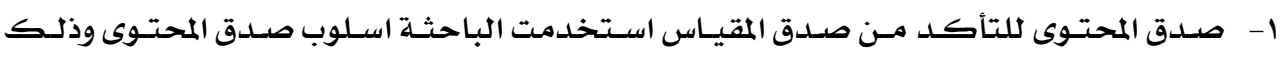

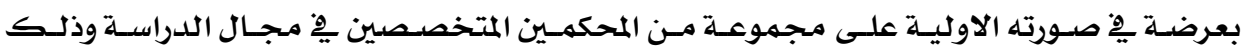

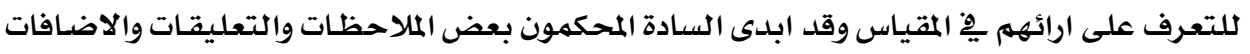

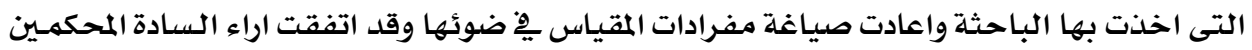

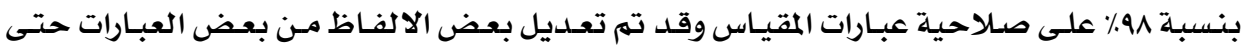




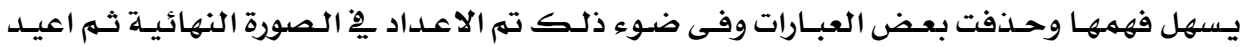

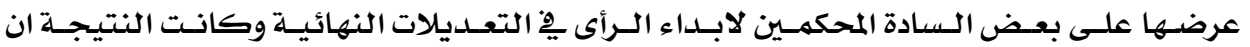
العبارات تقيس ما وضعت من اجلة علة.

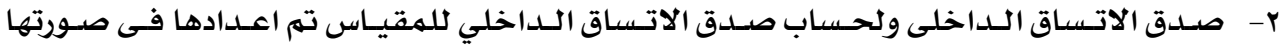

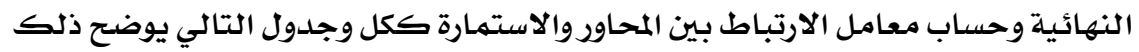

جدول (1)

معاملات الارتباط بين محاور مقياس الكفاءة الإدارية

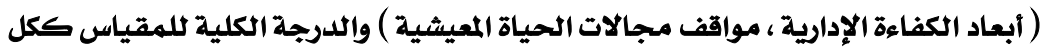

\begin{tabular}{|c|c|}
\hline معامل الارتباط & محاور مقياس الكفاءة الإدارية \\
\hline$* *$ * เV० & إدارة اللدخل المالي \\
\hline 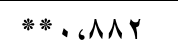 & إدارة الوقت والجهل \\
\hline **. . $94 \wedge$ & إدارة العلاقات الاجتماعية \\
\hline$* *$, ‘VV & إدارة الأمور الخاصة بالأبناء \\
\hline$* * \cdot ، \wedge \leq 7$ & مجال الفذاء \\
\hline$* * .6919$ & مجال الملابس \\
\hline$* * \cdot$ * $\wedge \cdot V$ & مجال المسكن وتجهزاته \\
\hline *** ، ^1 & مجال التعليم والترفيه \\
\hline
\end{tabular}

- يتضـح مـن جـدول (1) ان معـاملات الارتبـاط بـين محساور مقيـاس الكفـاءة الاداريـة ( ابعـاد الكفـاءة

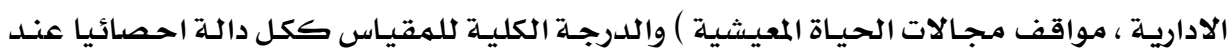
مستوي دلالة ا +.•مهما يدل علي تجانس محاور المقياس والدرجـة الكلية له

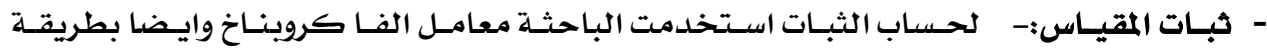

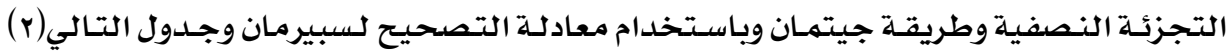
يوضح ذلك. 


$$
\text { جدول (r) }
$$

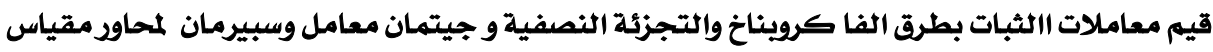

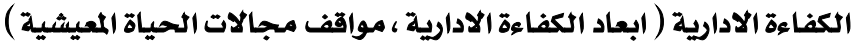

\begin{tabular}{|c|c|c|c|c|}
\hline جيتمان & سمامل الثبات & التجزئة النصفية الثبات & الفا كروبناخ الثبات & محاور مقياس الكفاءة الادارية \\
\hline$\cdot$, Ary & $\cdot 91$. & $\cdot$, Arq & $\cdot, \wedge \wedge \uparrow$ & ادارة الدخل المالي \\
\hline$\cdot, \wedge \xi \cdot$ & $\cdot, \wedge \wedge \vee$ & $\cdot, \mathrm{V9 \Lambda}$ & $\cdot, 10$ & ادارة الوقت والجهد \\
\hline$\cdot, 9 \cdot 8$ & -, 9rq & $\cdot, \Lambda 7 \vee$ & $\cdot, 914$ & ادارة العلاقات الاجتماعية \\
\hline$\cdot, \Lambda \cdot r$ & $\cdot, \wedge T \xi$ & $\cdot, \mathrm{V} / \mathrm{II}$ & $\cdot, \wedge 17$ & ادارة الامور الخاصة بالابناء \\
\hline$\cdot$, Vrr & $\cdot, \wedge \leqslant \vee$ & •, YY\& & •, ห^ฯ & مجال الفذاء \\
\hline$\cdot$, A9r & $\cdot, \wedge 7$. & $\cdot, \wedge \uparrow$ & $\cdot, 9 \cdot 7$ & مجال الملابس \\
\hline -, V97 & $\cdot, 9 \cdot 7$ & $\cdot, A T A$ & $\cdot, \lambda \cdot \wedge$ & مجال المسكن وتجهزاته \\
\hline$\cdot, \wedge 9$. & - ar. & •, nor & $\cdot, \wedge 99$ & مجال التعليه والترفيه \\
\hline •,Arq & $\cdot$, ArA & •, VAT & •, Arr & المقياس ككل \\
\hline
\end{tabular}

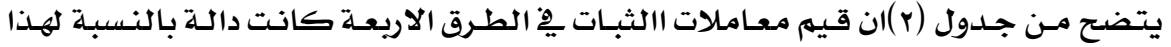

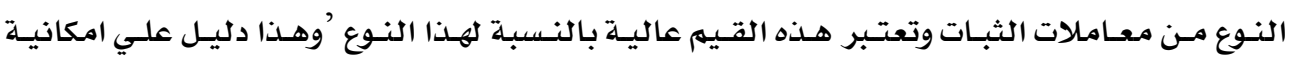
استخدام المقياس.

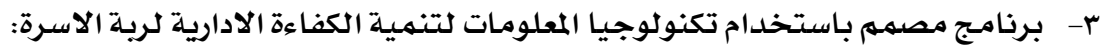
تم اعـداد البرنـامـج التـدربيى بحيـث يهـدف هـذا البرنـامـج إلى رفـع مسستوى الكفـاءة الإداريـة للريـة الاسـرة ِِّأربعة أبعاد وهي ( ادارة الدخل المالى ، ادارة الوقت والجهد ، ادارة العلاقات الاجتمهاعيـة ،

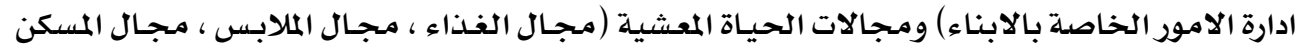

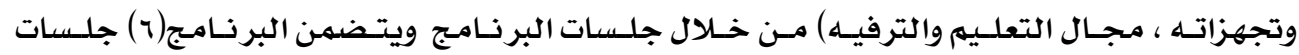
لتبيقها علي عينة البـحث التجريبيـة وفيما يلي توضيـح لمحتوي جلسات البرنامـج : 
جلدول (r) (r) (r)

محتوي الجلسات والاهداف التعليمية والوسائل والانشطة المستخدمة يِّ البرنامج

\begin{tabular}{|c|c|c|c|}
\hline الوسائل والانشطة & محتوي الجلسة & اهداف الجلسة & موضوع الجلسة \\
\hline البهـرض محتويــات الكمبيـوتر & 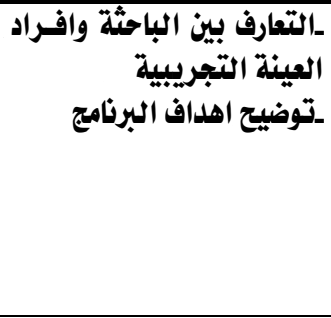 & 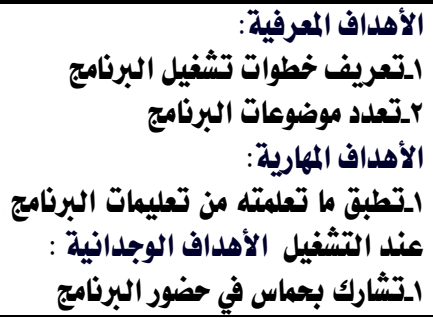 & للبرنامج \\
\hline 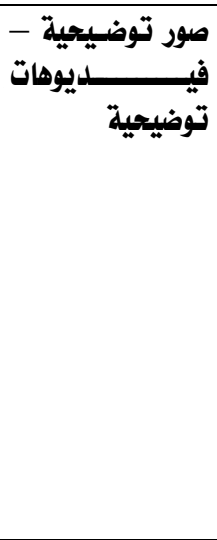 & 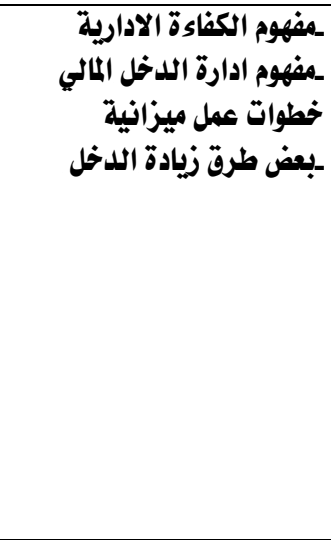 & 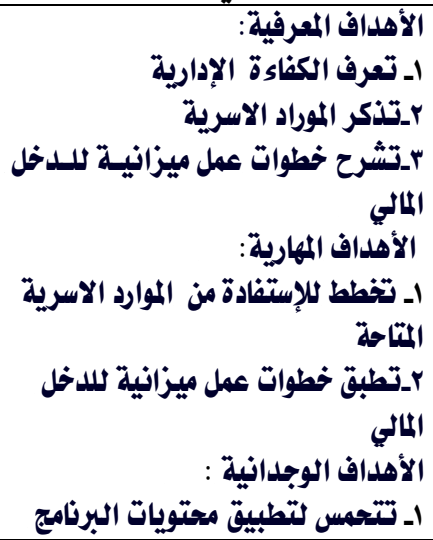 & 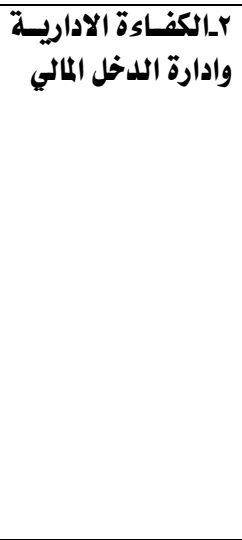 \\
\hline 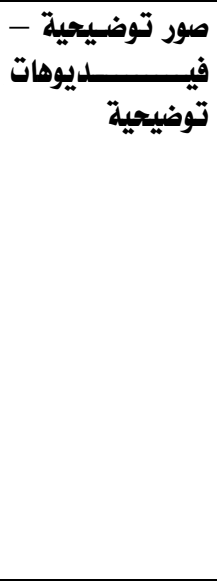 & 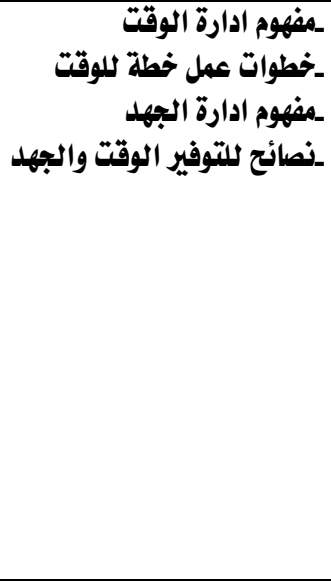 & 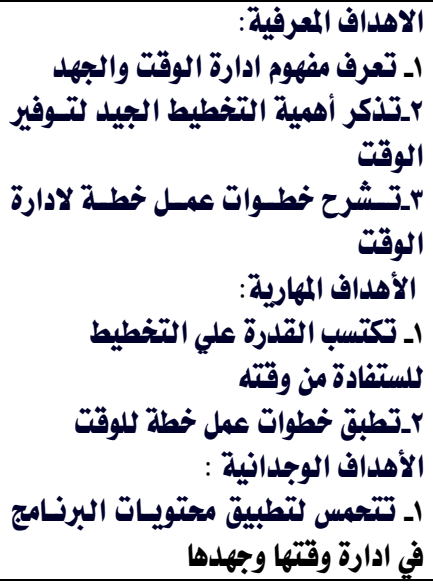 & والجهـدادة الوق \\
\hline 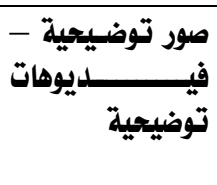 & 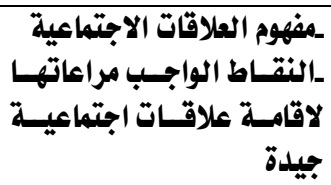 & الآهداف المعرفية: & الاجتماعية العلاقة \\
\hline
\end{tabular}




\begin{tabular}{|c|c|c|c|}
\hline & & 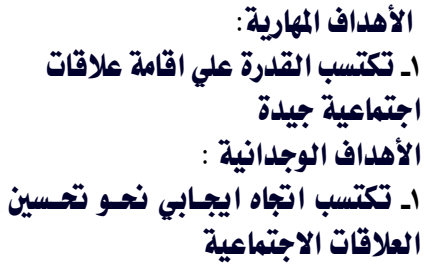 & \\
\hline 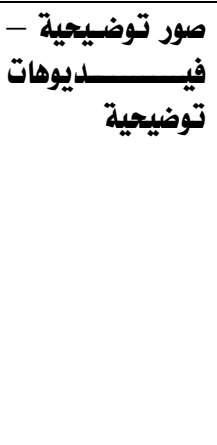 & 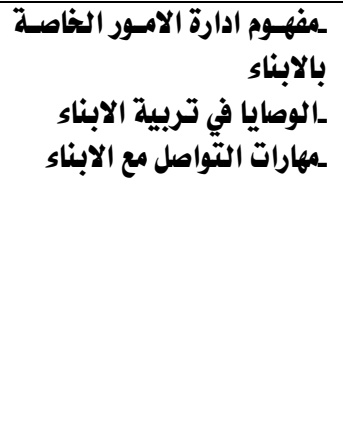 & 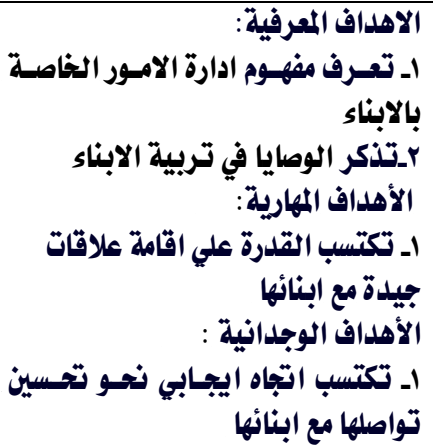 & 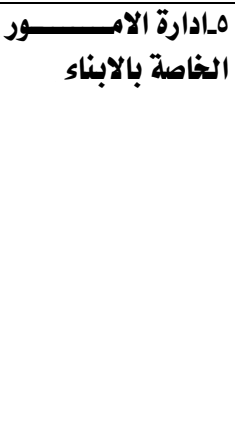 \\
\hline المقاييس & & نهايــة البرنـامج واجــراءات النطبيـتق & 7-الجلسة الختامية \\
\hline
\end{tabular}

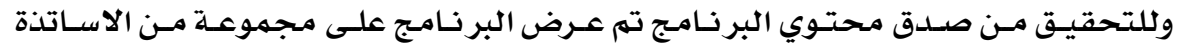

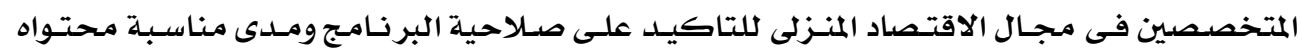

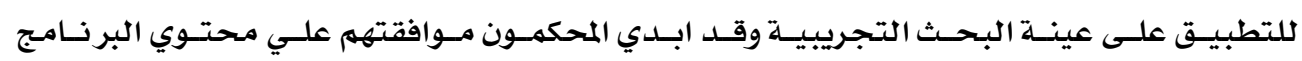

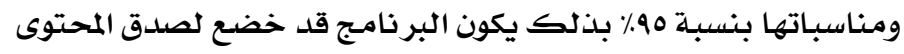
تطبيق البرنامسج :

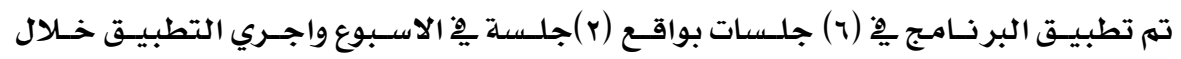

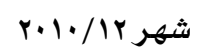
تقيييم البرنامج : تقمت

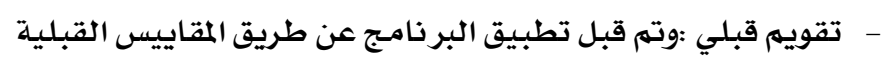
- تقويهم مرحلي :اثناء تطبيق البر نامجر والذي يتضمن نهو البرنامج وتقدمـه نحو تحقيق اهدافه

$$
\text { - تقويم نهائي :بتطبيق المقاييس مرة ثانية للتعرف علي اثر البرنامج }
$$

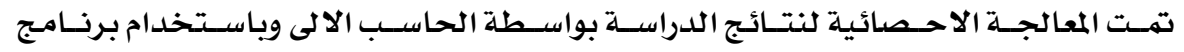

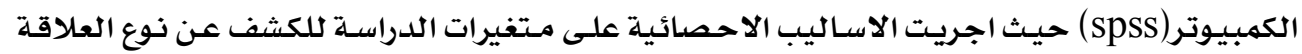

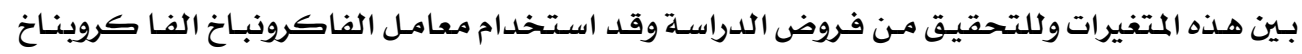

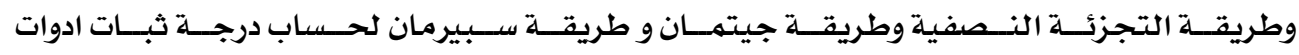


الدراسة،استخدام اختبـارات ( t-test ) و ( F-test ) لحساب الفـروق بـين مـتغيرات الدراسلةواستخدلام اختبار)(lsd) للمقارنات المتعددة.

الإطار النظري: - إنباري

تعتبر ادارة شئون الاسـرة من احدث العلوم الاداريـة التى تسـاعد الاسـرة على استخدام الموارد

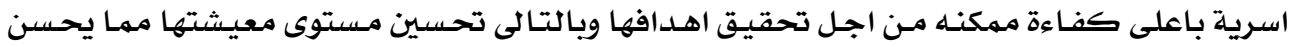

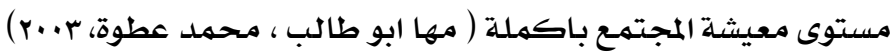

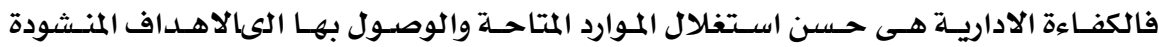

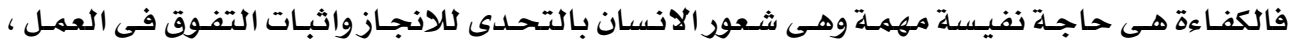

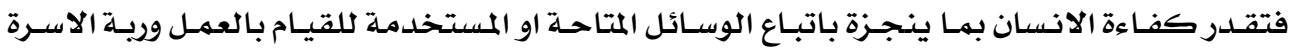

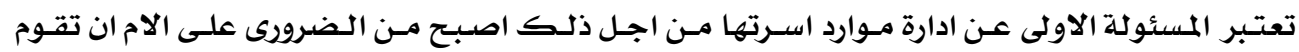

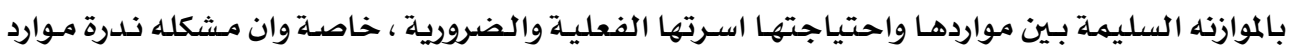

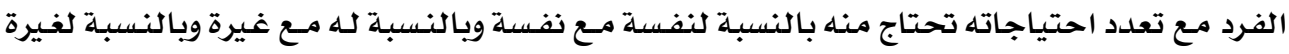

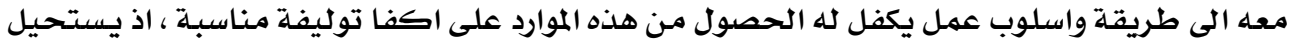

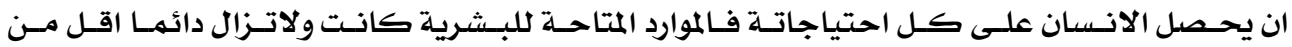

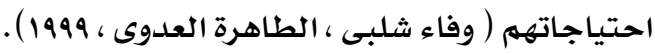

الكفاءة الإدارية:تعريف الكفاءة الادارية:.

تعـرف الكفـاءة الاداريسة بـانهـا الممارسـات الاداريـة التـى تتبعهـا الاسـرة فـى مجـالات الحيـاة

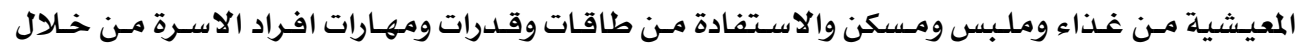

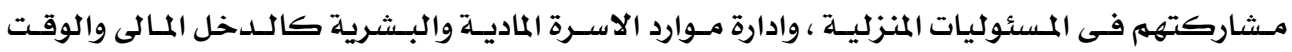

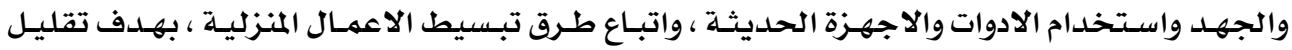

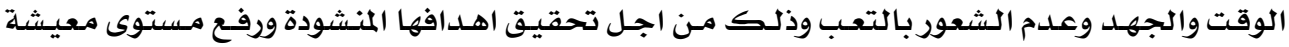

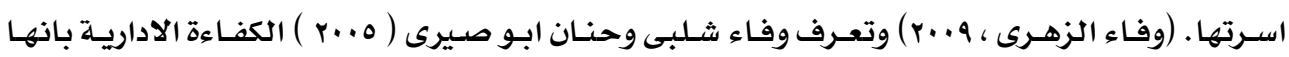

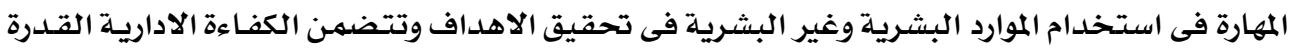

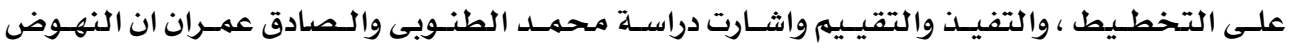

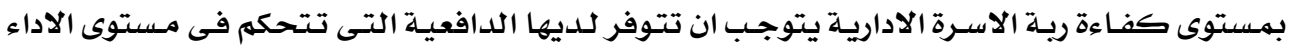

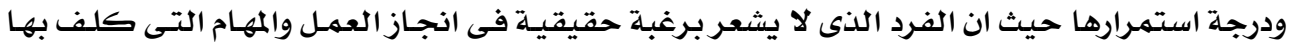

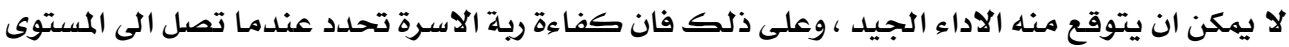

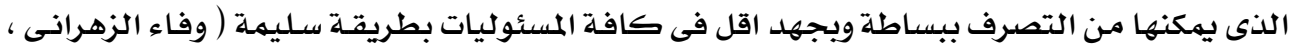

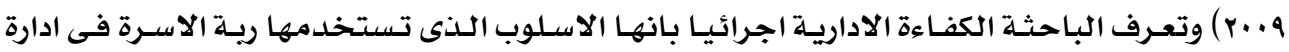

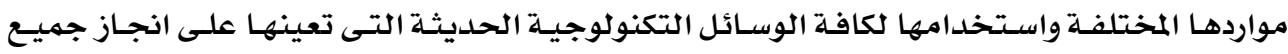

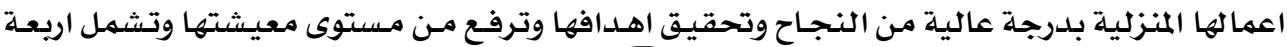


مجلة بحوث التربية النوعية - علد ro - مابريل r.lr

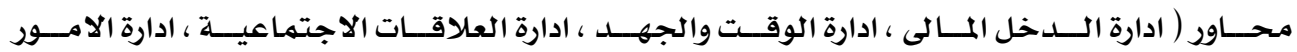

الخاصة بالابناء)

التعامل مع المستحدثات التكنولوجية المتطورة:

يتميز العصر الحاضر بتزايد المستحدثات التكنولوجية فى جميع المجالات ، ومـن الملاحظظ ان

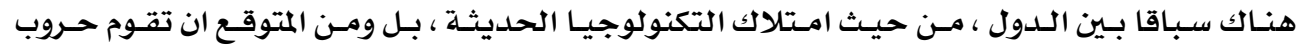
المستقبل بـين الدول بسبب المعلومات والتكنولوجيا ، كما ان كل دولـة اذا كـان لها ان تتفـوق على دول اخرى ، فان ذلك يكون بقـدر مـا تمتلكة مـن معلومـات وتكنولوجيـا حديثة مهـا يتطلسب تعلـم مهارات حياتية جديدة ، فاذا ارادت المراة ان تتعامل مـع المستحدثات التكنولوجيـا بهـتلف اشكال تنوعها ، واذا

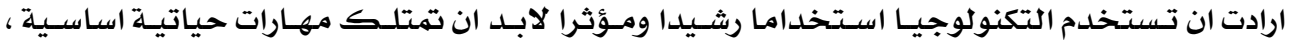

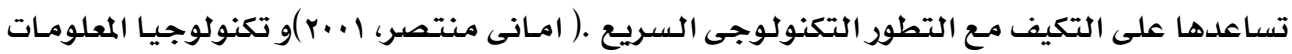
هـى التكنولوجيـا الالكترونيـة اللازمسـة لتجميــع واختـزان وتجهيـز وتوصـيـل المعلومــات ولتكنولوجيـا

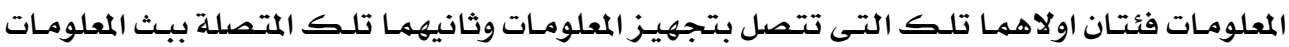
وتتطلب مثل هـذه التكنولوجيـا مهارات التعـامـل معهمها وافضل امكانيـة فى تحقيق الاهـداف ( حسـن

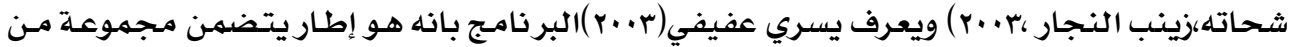
الخبر ات تقدم لمجموعة مـن الدارسين لتحقيق اهداف خاصدة يْ فترة محددة

$$
\text { نتائج الدراسة هناقشاتها وتفسيرها : - التحقق من صحة الفروض: }
$$

ا. توجل فروق ذات دلالة احصائية بين محاور مقياس الكفاءة الاداريـة لربـات أسـر عينـة البحث

$$
\text { (ابعاد الكفاءة الادارية، مجالات الحياة المعيشية) ومتغيرات الدارسية. }
$$

وللتحقـق مـن صسحة الفـرض قامست البـاحثـة باسـتخدلام اختبـار " ت "t-test وأيـضا تحليـل التباين الأحسادى " one way anova " على النحو التالي.

ا ا توجـد فـروق ذات دلالـة احصديائية بـين محساور مقيـاس الكفـاءة الاداريـة لربـات أسـر عينـة البحثث تبعا لعمل الامم. 
جلدول (ع)

دلالة الفروق بين افراد العينة الاساسية فى محاورالكفاءة الادارية تبعا لمتغيرعمل الام

\begin{tabular}{|c|c|c|c|c|c|c|c|}
\hline مستوى اللدالة & قيمة & الحرجية & العينة & الأنحراف & الحتوسط & المتفير & |الكفاءة الاذارية محاور مقاس \\
\hline \multirow{2}{*}{ 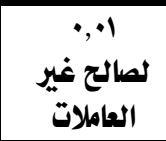 } & \multirow[b]{2}{*}{ ro, T\&Y } & \multirow[b]{2}{*}{ raA } & 187 & 11,070 & or,\{VY & تعمل & \multirow[t]{2}{*}{ |دارة الدخل المالي | } \\
\hline & & & IVs & 17,779 & A9,Irr & لا تعمل & \\
\hline \multirow{2}{*}{ 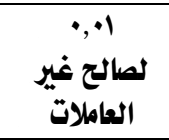 } & \multirow[b]{2}{*}{ Yr,OTY } & \multirow[b]{2}{*}{ raA } & Iry & 9,Arr & $\$ 1$, OVq & تعمل & \multirow[t]{2}{*}{ |دارة الوقت والجهر| } \\
\hline & & & IV乏 & $1 \cdot, 1 A V$ & 79, YOA & لا تعمل & \\
\hline \multirow{2}{*}{ غير دالة، } & \multirow{2}{*}{$\cdot, 9 \leqslant \varepsilon$} & \multirow{2}{*}{ raA } & $1 r 9$ & 17,171 & $\{Y,\{O Y$ & تعمل & \multirow{2}{*}{ الاجتماعية العلاقة } \\
\hline & & & IVE & $1 \%, r 9 A$ & $\{9, \cdot 7 r$ & لا تعمل & \\
\hline \multirow{2}{*}{ الصالح } & \multirow[b]{2}{*}{$r \cdot, \cdot r_{1}$} & \multirow[b]{2}{*}{ raA } & $1 r 7$ & $v, q \cdot 1$ & TV & تعمل & \multirow{2}{*}{ بالابناء الامور الخاصر } \\
\hline & & & IVE & 17,178 & $\{9,00\}$ & لا تعمل & \\
\hline \multirow{2}{*}{ 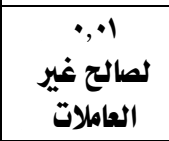 } & \multirow[b]{2}{*}{$M, \Lambda \varepsilon \cdot$} & \multirow[b]{2}{*}{ raA } & $1 r 9$ & 0,10 & $r r,+H$ & تعمل & \multirow[t]{2}{*}{ مجال الفذاء } \\
\hline & & & IVE & Y, YTS & $r V, \wedge \leq \varepsilon$ & لا تعمل & \\
\hline \multirow{2}{*}{ 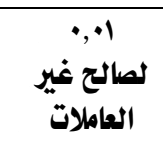 } & \multirow[b]{2}{*}{$r Y, O \leqslant \wedge$} & \multirow[b]{2}{*}{ raA } & $1 Y 7$ & $r, r v$. & $1 \cdot, 7 \mathrm{FV}$ & تعمل & \multirow[t]{2}{*}{ مجال الملابس } \\
\hline & & & IV£ & $r, 0 \leqslant Y$ & IV, 09Y & لا تعمل & \\
\hline \multirow{2}{*}{ 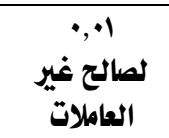 } & \multirow{2}{*}{ rI, Yor } & \multirow[b]{2}{*}{ raA } & 179 & r, YAY & $11,07 r$ & تعمل & \multirow{2}{*}{ وثجهزاته المسكن } \\
\hline & & & IVs & r,Irq & $19,1 \leqslant 9$ & لا تعمل & \\
\hline \multirow{2}{*}{ 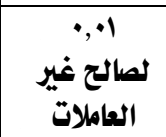 } & \multirow[b]{2}{*}{$17, \wedge \wedge$. } & \multirow[b]{2}{*}{ raA } & $1 r 9$ & $1, \wedge \leqslant \wedge$ & $1 \cdot, 7 A r$ & تعقل & \multirow{2}{*}{ والترفيه التعليه } \\
\hline & & & IV乏 & $0,10 \mathrm{r}$ & IA, YAY & لا تعمل & \\
\hline
\end{tabular}

يتضح من الجدول السابق ان هناك فروقا ذات دلالة احصائية بين المراه العاملة وغير العاملـة

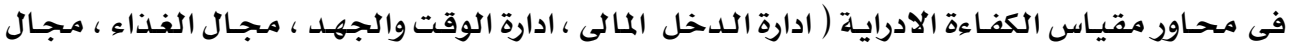

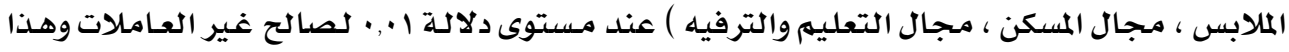

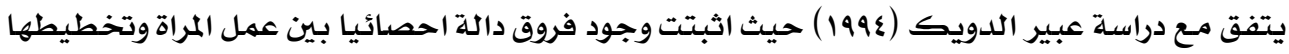

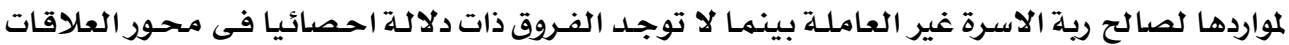

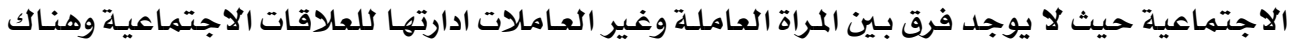

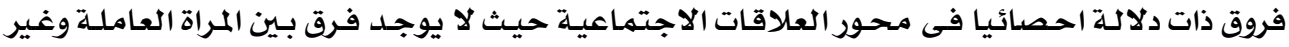

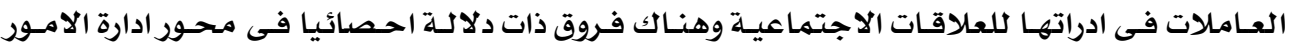


مجلة بحوث التربية النوعية - علدد ب - مبريل r.lr

الخاصة بالابناء عند مستوى دلالة ا •. • لصالح المراة العاملـة وترحسع الباحثة ذلك الى الى اكتساب ريسة

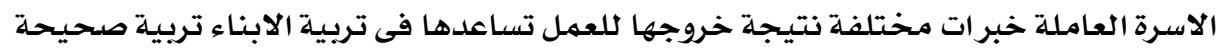

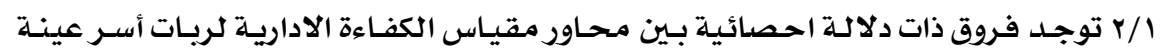

البحث تبعا لدخل.

جدول (0)

جدول تحليل التباين بين افراد العينة الاساسية فى محاور الكفاءاة الادارية تبعا لمتغير الدخل

\begin{tabular}{|c|c|c|c|c|c|c|}
\hline مستوى & قيمة "ف" & متوسط المربعات & الحرجية & مجموع المربعات & مصدر التباين & المتفير \\
\hline$\cdot, \cdot 1$ & $07,87 r$ & $\begin{array}{l}\{7 Y \wedge \cdot, Y \xi Y \\
\wedge 19,7 \wedge \varepsilon\end{array}$ & $\begin{array}{l}r \\
r a r \\
\text { raq }\end{array}$ & 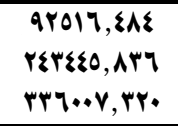 & داخل المجموعات المجموعات & ادارة الداخلي \\
\hline$\cdot, \cdot 1$ & $\xi r, r \xi 1$ & $\begin{array}{l}\text { 1990r,070 } \\
\varepsilon \cdot 7, \cdot V r\end{array}$ & $\begin{array}{l}r \\
\text { rar } \\
\text { raq }\end{array}$ & $\begin{array}{c}r 99 \cdot 0,171 \\
17 \cdot 7 \cdot r,\{77 \\
17 \cdot 0 \cdot 1,097\end{array}$ & داخل المجموعات المجموعات & ادارة الوقت \\
\hline$\cdot, \cdot 1$ & OV,Oß\} & $\begin{array}{l}\text { IVEIA,OrY } \\
r+r, 799\end{array}$ & $\begin{array}{l}r \\
\text { rar } \\
\text { raq }\end{array}$ & 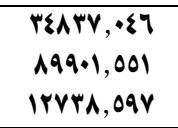 & داخل المجموعات المجموعات & 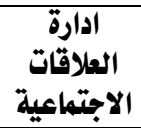 \\
\hline$\cdot, \cdot 1$ & 01,090 & $\begin{array}{l}\text { r\&s70, Yor } \\
\text { \&IY, O\&Y }\end{array}$ & $\begin{array}{l}r \\
\text { rar } \\
\text { raq }\end{array}$ & $\begin{array}{l}\xi \wedge q r \mid, r+q \\
\mid r \varepsilon \cdot \cdot q, \wedge \varepsilon \cdot \\
\text { Irra\&I, I\&Y }\end{array}$ & داخل المجموعات المجموعات & الخارة الامثور \\
\hline$\cdot, \cdot 1$ & $\xi_{\bullet}, r \varepsilon_{\bullet}$ & $\begin{array}{l}\text { VEYI, Yrq } \\
\text { IAr,970 }\end{array}$ & $\begin{array}{l}r \\
r q Y \\
r q 9\end{array}$ & 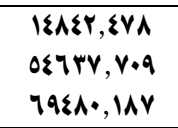 & داخل المجموعات المجموعات المجلى & مجال الفذاء \\
\hline$\cdot,+1$ & $\xi V, \bullet A r$ & $\begin{array}{l}1 \leqslant 7, Y Y q \\
r 1, \bullet \& \eta\end{array}$ & $\begin{array}{l}r \\
\text { rar } \\
\text { raq }\end{array}$ & $\begin{array}{l}\text { rarr, Srr } \\
\text { qrr., 7ry } \\
\text { IrISE, } 1 \cdot 9\end{array}$ & داخل المجموعات المجموعات & الملابس \\
\hline$\cdot, \cdot 1$ & $\xi \cdot, 9 \xi \%$ & $\begin{array}{l}I r r \cdot, \xi+r \\
r \cdot, \cdot O r\end{array}$ & $\begin{array}{l}r \\
\text { raY } \\
\text { raq }\end{array}$ & 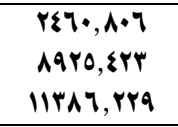 & داخل المجمهوعات المجموعات & وتجهزالته المسكن \\
\hline$\cdot,+1$ & $0 \xi, \cdot 9 r$ & $\begin{array}{l}\text { YVA9,Yr. } \\
01,070\end{array}$ & $\begin{array}{l}r \\
\text { rar } \\
\text { raq }\end{array}$ & 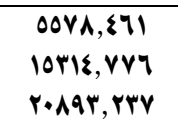 & داخل المجموعات المجموعات & والتجرفييم \\
\hline
\end{tabular}

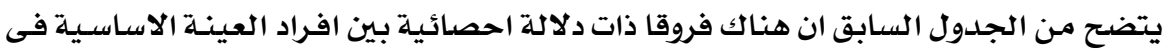

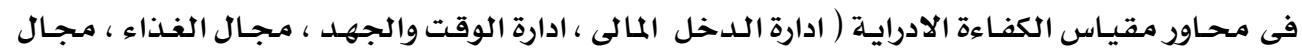

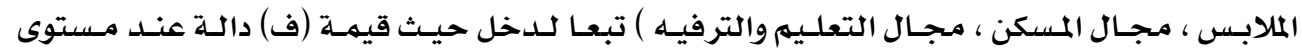
دلالة ا.,.

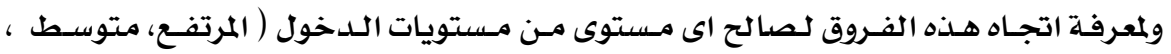

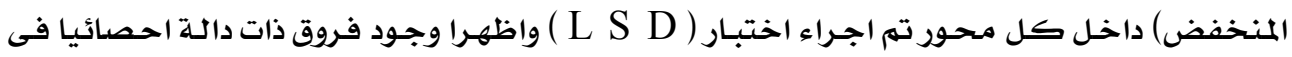


بعد الدخل المالى بين مستويات الدخول المختلفة للاسر لصالح المستوى المرتفع عند مستوى دلالـة ا ., .

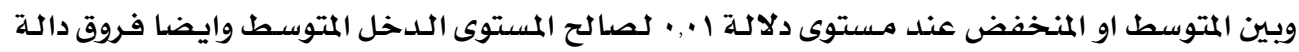

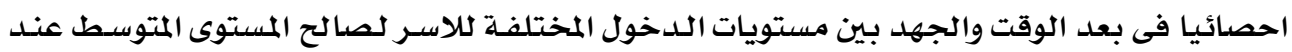

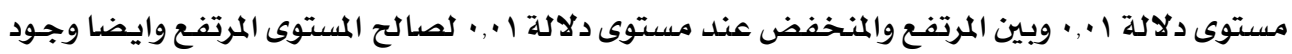

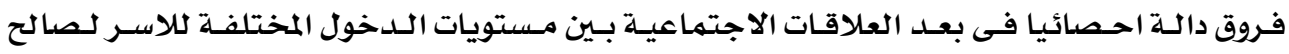

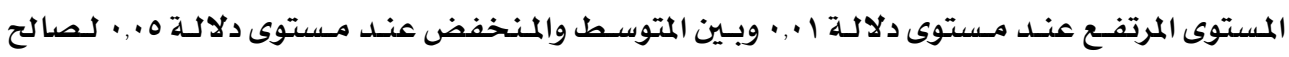

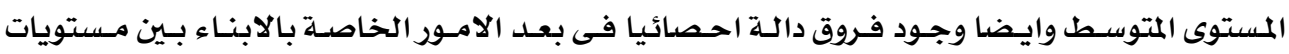

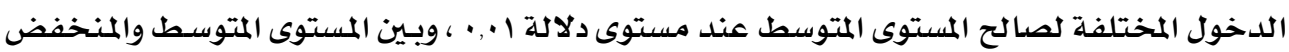

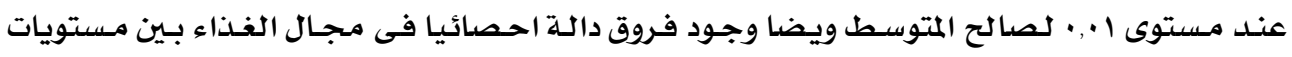

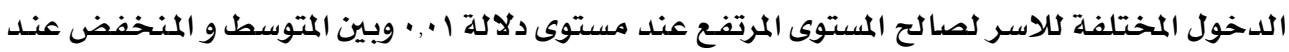

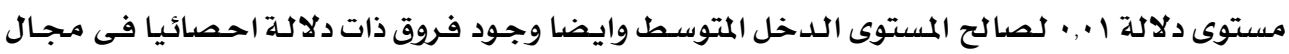

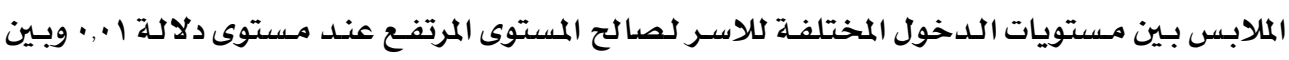

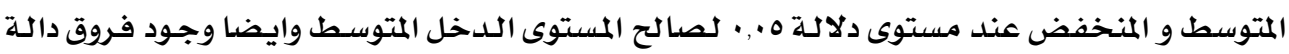

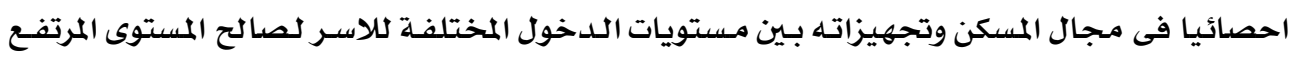

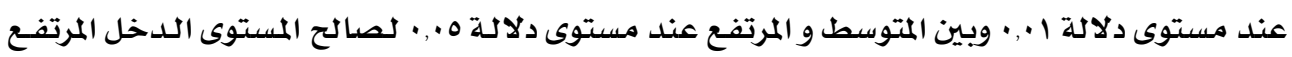

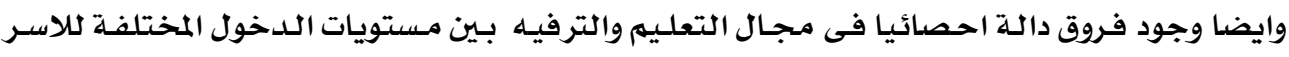

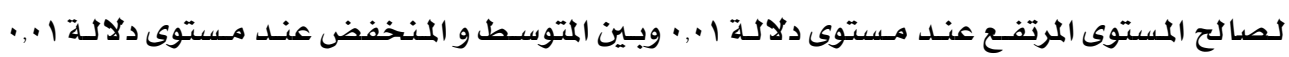

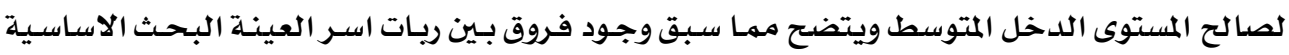

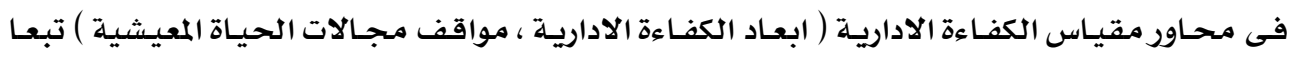

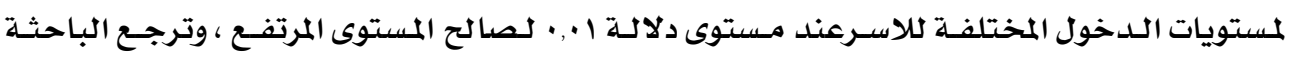

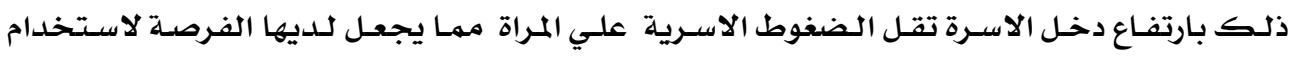

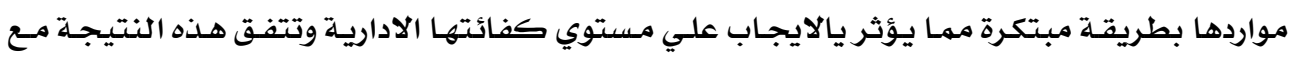

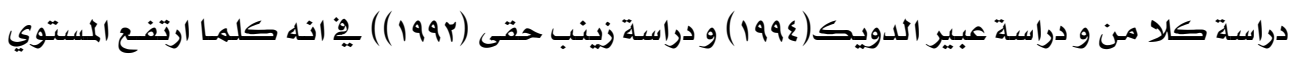

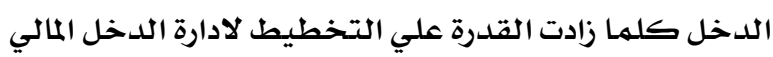

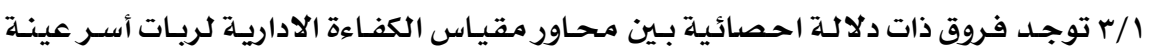

البحث تبعا لمدة الحياة الزوجية. 
جدول (†)

جدول تحليل التباين بين افراد العينة الاساسية فى محاور الكفاءاة الادارية تبعا لمتغير مدة الحياة الزوجية

\begin{tabular}{|c|c|c|c|c|c|c|}
\hline مستوى & قيمة "ف" & متوسط المربعات & الحرجات & مجموع المربعات & مصدر التباين & التفير \\
\hline$\cdot, \cdot 1$ & §l, rYo & $\begin{array}{l}\text { YYYAD,00\& } \\
\text { TY1,000 }\end{array}$ & $\begin{array}{c}r \\
r a r \\
r q q\end{array}$ & $\begin{array}{l}000 r 1,1 \cdot 1 \\
199801, \lambda \cdot 9 \\
r 00 \cdot r r, 91 Y\end{array}$ & دأخل المججموعات & ادارة الداخل \\
\hline$\cdot, \cdot 1$ & $\varepsilon q, r v \varepsilon$ & $\begin{array}{l}\text { YY.YY,YYT } \\
O \& Y, O \cdot .\end{array}$ & $\begin{array}{l}r \\
r q r \\
r a q\end{array}$ & 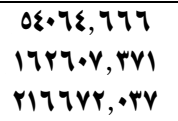 & داخيل المجهموعات & ادارة الوقت \\
\hline$\cdot, \cdot 1$ & $04, \xi H Y$ & $\begin{array}{l}\text { arll,orA } \\
170, \text { ryr }\end{array}$ & $\begin{array}{l}r \\
\text { rar } \\
\text { raq }\end{array}$ & 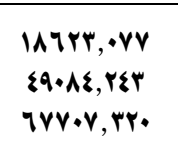 & دأخل المجموعات & الاجمتامعاتة ادماتي \\
\hline$\cdot,+1$ & \{A,orq & $\begin{array}{l}\text { rqr+9,orq } \\
\text { osr,17r }\end{array}$ & $\begin{array}{l}r \\
\text { rar } \\
\text { raq }\end{array}$ & 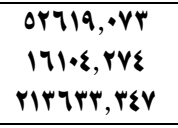 & داخلين المججموعات & 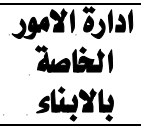 \\
\hline$\cdot, \cdot 1$ & $01,\{94$ & $\begin{array}{l}\text { YAOA, IAS } \\
\text { lOr, } 7.0\end{array}$ & $\begin{array}{l}r \\
\text { rar } \\
\text { raq }\end{array}$ & 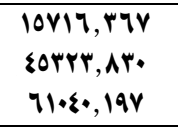 & داخيز المجهوعات & مجال الغذاء \\
\hline$\cdot, \cdot 1$ & $01,0 \leqslant 7$ & $\begin{array}{l}\text { IVIE,IOr } \\
\text { rr,roo }\end{array}$ & $\begin{array}{l}r \\
r q 4 \\
r a q\end{array}$ & $\begin{array}{l}r \xi r \wedge, r \cdot \xi \\
9 \Lambda r q, r \Delta \Lambda \\
1 r r \cdot 0, \cdot 7 r\end{array}$ & داخيل المجموعات & الملإبس \\
\hline$\cdot, \cdot 1$ & §1, ₹ๆ. & $\begin{array}{l}19 \cdot 0,7 \cdots \\
\$ 0,97 \mathrm{r}\end{array}$ & $\begin{array}{l}r \\
r a r \\
r 99\end{array}$ & 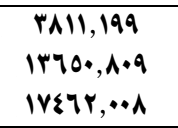 & داخيل المجهوعات & وتجهزاته المسكن \\
\hline$\cdot, \cdot 1$ & Or,VYA & $\begin{array}{l}\text { IrAY, Y^o } \\
\text { r\&,\&०Y }\end{array}$ & $\begin{array}{l}r \\
\text { rar } \\
\text { raq }\end{array}$ & 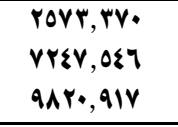 & داخيل المجهموعات & والتونيم \\
\hline
\end{tabular}

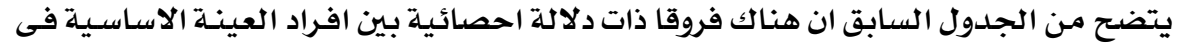

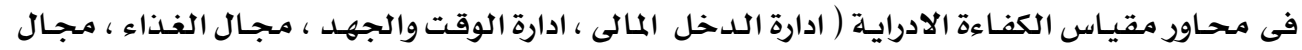

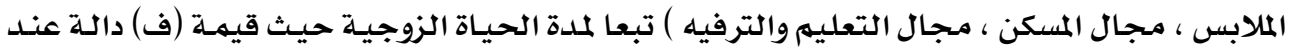

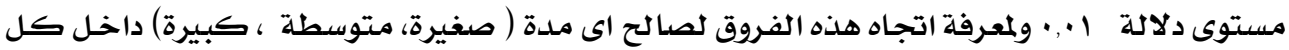

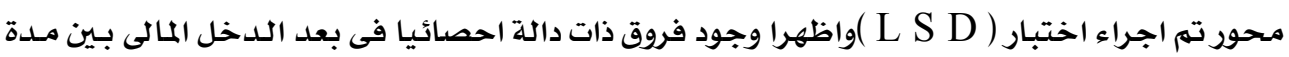

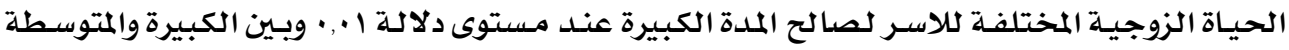

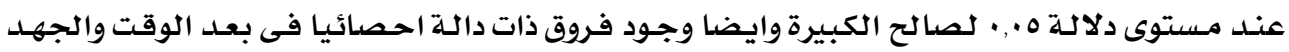

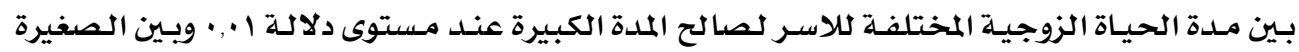

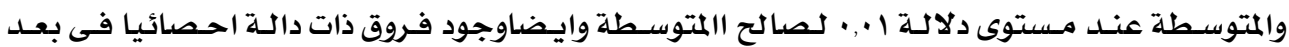

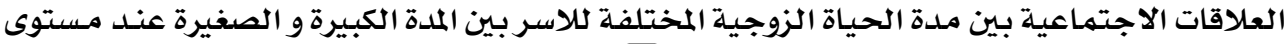


دلالـة ا., • لصالح الكبيرة وبـين المتوسـة والصغيرةعند مستوى دلالـة ا ,. • لصالح المتوسطة وايضا

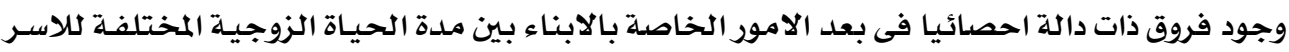

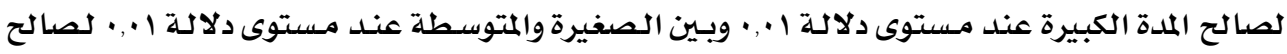

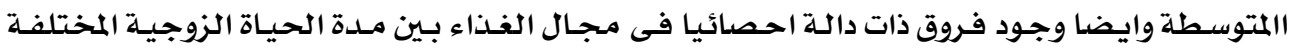

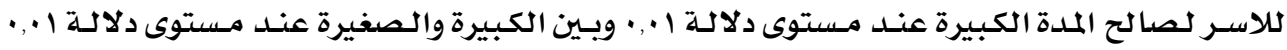

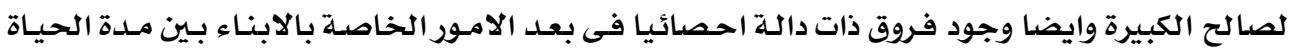

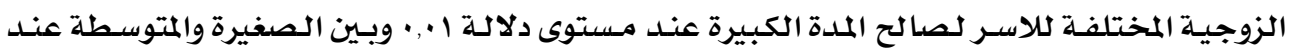

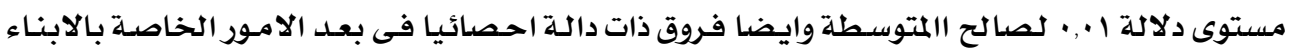

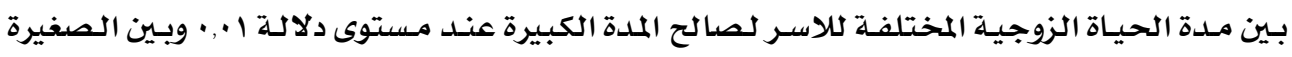

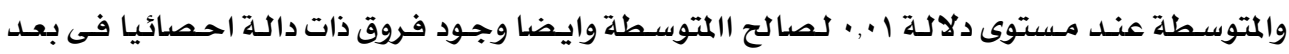

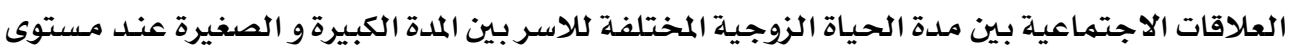

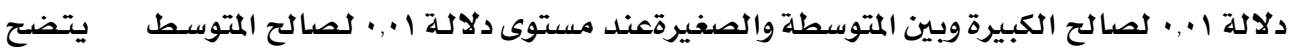

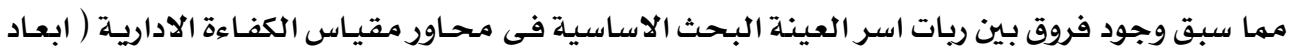

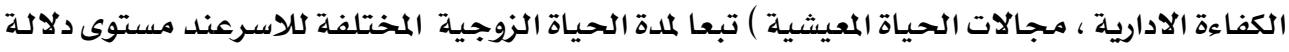

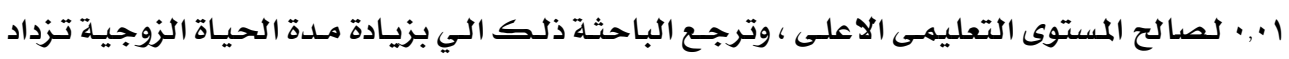

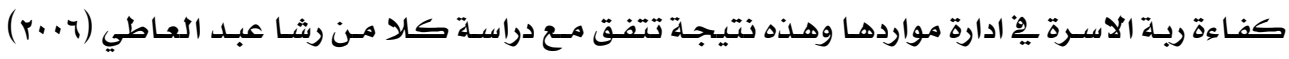

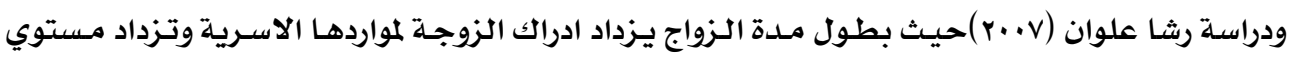

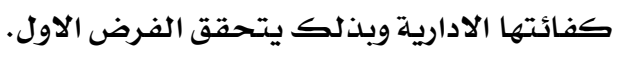

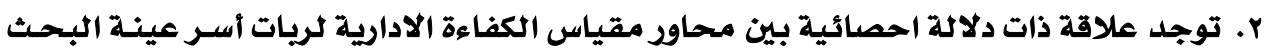

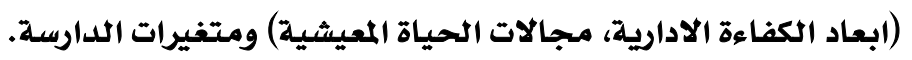
وللتحقق من صحسة الفرض تم إيجاد معامل الارتباط بيرسون بين المتغيرات.

جدول (v)

مصفوفة معاملات الارتباط بين محاور الكفاءة الادارية و بين متغيرات الدراسة

\begin{tabular}{|c|c|c|c|c|c|c|c|c|c|}
\hline ككل الكفارية & والتمليم & وتجهيزته & الملابس & الغذاء & الإراصة الامور & 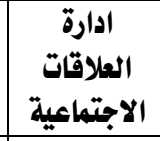 & والوقت & الدارخل & المتفير \\
\hline$\because * \cdot$ * V.V & $* *, \wedge Y \leq$ & $* * *, q \cdot V$ & $* *, \vee \vee \neg \varepsilon$ & **, , q 4 & *** • 9.0 & ***، ، AYr & *. . & $* * \cdot ، \Lambda \cdot \vee$ & مهنة \\
\hline$=* \cdot .9, r$ & $*$ • , . . & $* *, \wedge \vee r$ & $* *, \vee \vee 01$ & $* *, \Lambda \cdot r$ & $* *$ * ، $\wedge \varepsilon \Psi$ & * & $* *$ * ، $\wedge \vee q$ & ** , $6 V \Psi \varepsilon$ & ملدة الجياز \\
\hline ** , GVY & $* *, \vee Y q$ & $* *, \wedge \leqslant \wedge$ & 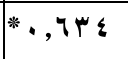 & $* *, v r v$ & *., IYA & $* * \cdot, \vee \bullet \wedge$ & ***، • & $* * .941$ & دخل الاسر| \\
\hline
\end{tabular}

• • دال عند مستوى دالة ا.,. . دال عند مستوى دالة ه., . 


\section{يتبين من الجدول السابق}

وجود علاقة ارتباطية موجبة بـين مهنـة الام و كـلا مـن محساور مقيـاس الكفـاءة الاداريـة لربـات أسـر

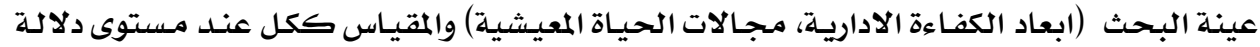

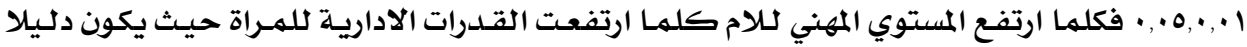

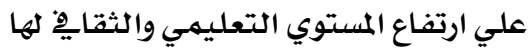

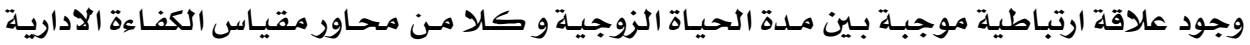

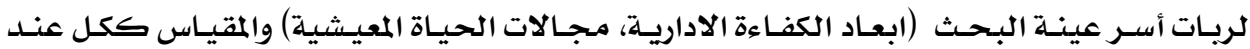

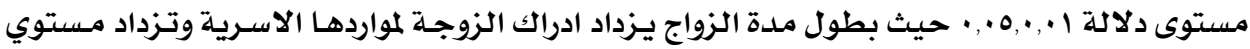
كفائتها الادارية دلاله وجود علاقة ارتباطية موجبة بين مستوي الدخل وكـلا مـن محساور مقياس الكفـاءة الاداريـة لربـات

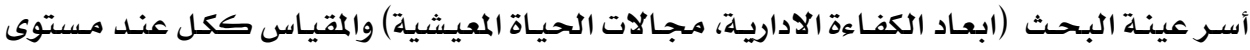

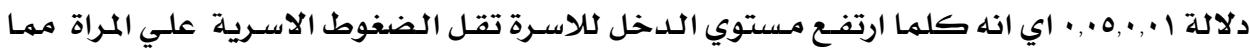

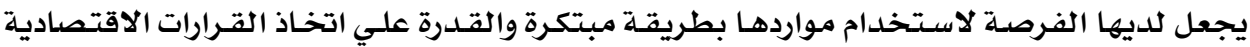

$$
\text { وبذلك يتحقق الفرض الثاني. }
$$

r. توجد فروق ذات دلالـة احصائية بـين متوسـات درجـات العينـة التجريبيـة للتطبيـق القبلي

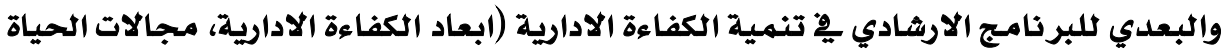

$$
\text { المعيشية) لرية الاسرة لصائح التطبيق البعدي. }
$$

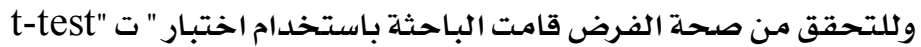

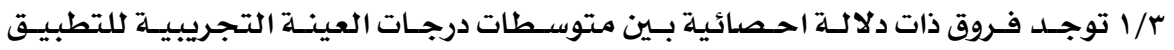

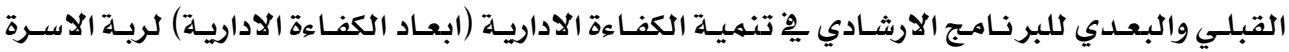
لصالح التطبيق البعدي. 


\section{(^) جدول)}

الفروق بين متوسطات درجات التطبيق القبلي والبعدي للبرنامج الارشادي

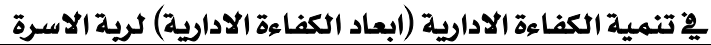

\begin{tabular}{|c|c|c|c|c|c|c|c|c|}
\hline في اتجاه & مستوى & 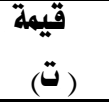 & الحرية & العينة & الالمعراف & الحستوسط & التطبيق & ابعاد الكفاءة \\
\hline \multirow{2}{*}{ البعدي } & \multirow{2}{*}{$\cdot, \cdot 1$} & \multirow{2}{*}{ rr, rYq } & \multirow{2}{*}{09} & \multirow{2}{*}{7.} & $17,\{r A$ & $0 ., 197$ & قبلي & \multirow{2}{*}{ ادارة الداخل } \\
\hline & & & & & $\boldsymbol{\xi}, \wedge \wedge \mathrm{r}$ & $9 \Lambda, \wedge \vee 0$ & بعدي & \\
\hline \multirow{2}{*}{ البعدي } & \multirow{2}{*}{$\cdot, \cdot 1$} & \multirow{2}{*}{$r q, r \wedge A$} & \multirow{2}{*}{09} & \multirow{2}{*}{7.} & $9, \sum 71$ & $\xi \cdot, r \cdot \bullet$ & قبلي & \multirow{2}{*}{ ادارة الوقت } \\
\hline & & & & & $\xi, r \leqslant Y$ & 19,077 & بعدي & \\
\hline \multirow[b]{2}{*}{ البعدي } & \multirow[b]{2}{*}{$\cdot, \cdot 1$} & \multirow[b]{2}{*}{ r६,§॥r } & \multirow[b]{2}{*}{$\Delta q$} & \multirow[b]{2}{*}{7.} & $V,\{0\}$ & $\Psi \&, \wedge 1\rceil$ & قبلي & \multirow{2}{*}{ الاجتماعية العاتة } \\
\hline & & & & & $r, q \leqslant Y$ & $V \cdot, r r \cdot$ & بعدي & \\
\hline \multirow[b]{2}{*}{ البعدي } & \multirow[b]{2}{*}{$\cdot,+1$} & \multirow[b]{2}{*}{$r \cdot,\{91$} & \multirow[b]{2}{*}{09} & \multirow[b]{2}{*}{7.} & $11, \wedge Y \xi$ & $\varepsilon r, q \wedge r$ & قبلي & \multirow{2}{*}{ الخارة|لامة الابناء } \\
\hline & & & & & $\xi, \leqslant 9$. & $r v, r v 1$ & بعدي & \\
\hline \multirow{2}{*}{ البعدي } & \multirow{2}{*}{$\cdot,+1$} & \multirow{2}{*}{ rq,rqะ } & \multirow{2}{*}{09} & \multirow{2}{*}{7.} & $\varepsilon \cdot \vee \wedge \wedge$ & 179,197 & قبلي & \multirow{2}{*}{ المجهوع } \\
\hline & & & & & V, QYY & rrq, \& & بعدي & \\
\hline
\end{tabular}

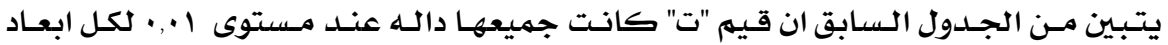

الكفـاءة الاداريـة كربـة الاسـرة ( ادارة الـدخل المالى ، ادارة الوقت والجهـد ، ادارة العلاققات الاجتمهاعيـة ،

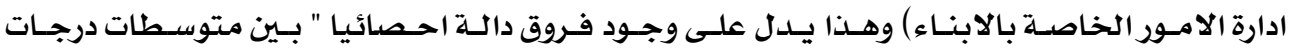
التطبيق القبلى والبعدى فى مستوى الكفاءة الادارية لصالح التطبيق البعدى ولتحديد حجم تاثير المتغير المستقل استخدمت البـاحثة مـربع ايتا n2 ) ويمكن حساب قيمـة مربـع ايتا عن طريق المعادلة التاليـة

\begin{tabular}{|r|r|}
\hline $\mathrm{n}^{2}=$ & $\mathrm{T}^{2}$ \\
\cline { 2 - 2 } & $\mathbf{T}^{\mathbf{2}}+\mathbf{d f}$ \\
\hline
\end{tabular}

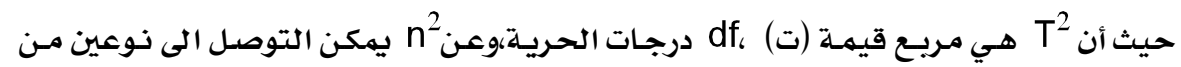
المعلومات:ا - يمكن تحويل قيمهة (n²) الى قيمة d وهى تعبر عن حجم التاثير فى التجرية.

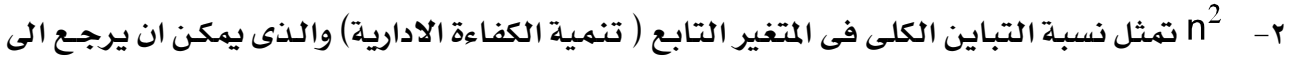

المتغير المستقل ( برنامج الكمبيوتر المصهم لتنهية الكفاءة الادارية ) . ويتحدد حجم التاثير وما اذا كان كبيرا او صغيرا او متوسطا كالاتى :

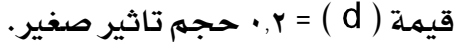

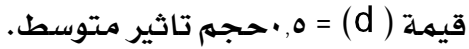




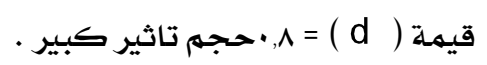

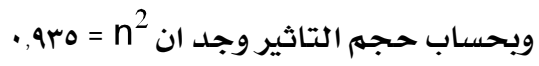

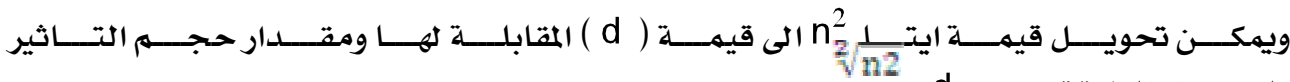
$\frac{\sqrt{n 2}}{\sqrt{1-n 2}} d==v, 09$ باستخدام العلاقن تحوين إذن حجم التاثير كبير.

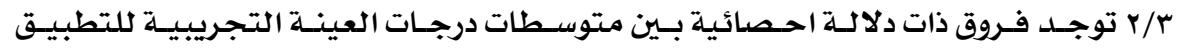

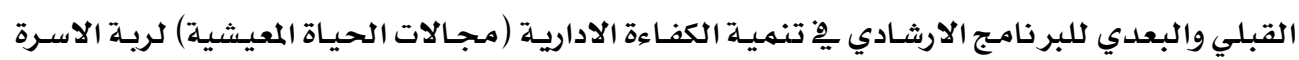
لصالح التطبيق البعدي والبعدي لبرنامي

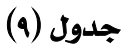

الفروق بين متوسطات درجات التطبيق القبلي والبعدي للبرنامجج الارثادي (هاءي

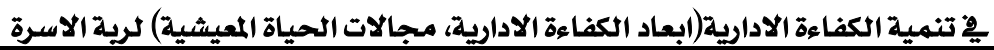

\begin{tabular}{|c|c|c|c|c|c|c|c|c|}
\hline فئي & مستوى & $\begin{array}{r}\text { قيمة } \\
\end{array}$ & الحرجية & العينة & الالمعراف & الحسابي & التطبيق & مجالات الحياة \\
\hline \multirow{2}{*}{ البعلدي } & \multirow{2}{*}{$\cdot, \cdot 1$} & \multirow{2}{*}{$r A, 1 \wedge 9$} & \multirow{2}{*}{$\Delta q$} & \multirow{2}{*}{7.} & 8,990 & YY,Z17 & قبلي & \multirow{2}{*}{ مجال الفذاء } \\
\hline & & & & & r,ATr & $\{r, \xi \leqslant\rceil$ & بعلدي & \\
\hline \multirow{2}{*}{ البعدي } & \multirow{2}{*}{$\bullet,+1$} & \multirow{2}{*}{$11, \cdot 79$} & \multirow{2}{*}{$\Delta q$} & \multirow{2}{*}{7.} & $r, 001$ & $1 \cdot, Y 17$ & قبلي & \multirow{2}{*}{ مجال الملابس } \\
\hline & & & & & 1,119 & $\mathrm{IV}, \wedge \wedge \mathrm{A}$ & بعلدي & \\
\hline \multirow{2}{*}{ البعلدي } & \multirow{2}{*}{$\cdot, \cdot 1$} & \multirow{2}{*}{$r r, q \cdot r$} & \multirow{2}{*}{09} & \multirow{2}{*}{7.} & $r, 001$ & $11, Y 17$ & قبلي & \multirow{2}{*}{ وتجال المسكز } \\
\hline & & & & & $1, \vee \wedge \neg$ & $r 1,1 \leqslant 0$ & بعلدي & \\
\hline \multirow{2}{*}{ البعدي } & \multirow{2}{*}{$\cdot, \cdot 1$} & \multirow{2}{*}{$\$ 1, \cdots \wedge$} & \multirow{2}{*}{89} & \multirow{2}{*}{7.} & $1, v 91$ & $1 \cdot,\{77$ & قبلي & \multirow{2}{*}{ مجال التمليه } \\
\hline & & & & & $1,9 \& V$ & $Y \xi, \&\{Y$ & بعلي & \\
\hline \multirow{2}{*}{ البعدي } & \multirow{2}{*}{$\cdot, \cdot 1$} & \multirow{2}{*}{ IrT,Y } & \multirow{2}{*}{09} & \multirow{2}{*}{7.} & I., MIV & 08, YII & قبلي & \multirow{2}{*}{ المجموع } \\
\hline & & & & & $7,0 \leqslant A$ & $1.9,917$ & بعلدي & \\
\hline
\end{tabular}

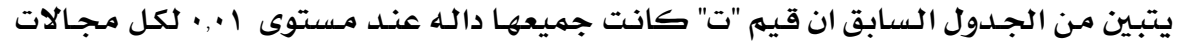

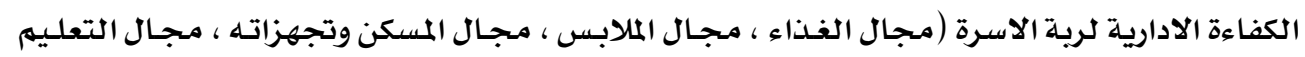

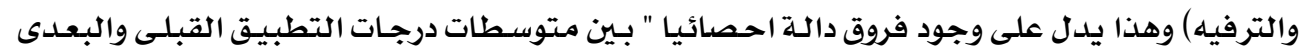

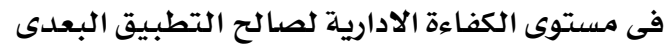
ولتحديد حجم تاثير المتغير المستقل استخدمت الباحثة مريع ايتا (n2 ) ويمكن حساب قيمسة

\begin{tabular}{|l|r|}
\hline $\mathrm{n}^{2}=$ & $\mathrm{T}^{2}$ \\
\cline { 2 - 2 } & $\mathbf{T}^{\mathbf{2}}+\mathbf{d f}$ \\
\hline
\end{tabular}
مربع ايتا عن طريق المعادلة التالية 


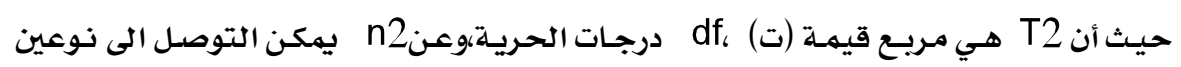
من المعلومات:

1- يمكن تحويل قيمة (n2) الى قيمة d وهى تعبر عن حجم التاثير فى التجرية.

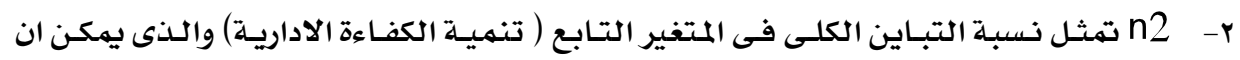
يرجـع الى المتغير المستقل ( برنامـج الكمبيوتر المصمهم لتتمية الكفاءة الادارية ) . ويتحلدد حجم التاثير وما اذا كان كبيرا او صغيرا او متوسطا كالاتى :

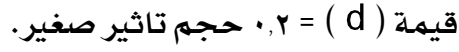

$$
\begin{aligned}
& \text { قيمة ( d ) = (d ) حجم تاثير متوسط. }
\end{aligned}
$$

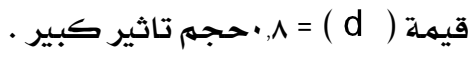

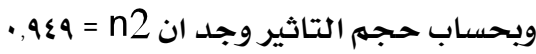

ويمكن تحويل قيمة ايتا n2 الى قيمة ( d ) المقابلة لها ومقدار حجم التاثير $\frac{\sqrt[2]{n 2}}{\sqrt{1-n 2}} d==$ باستخدام العلاقة

إذن حجم التاثير كبير - إن

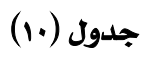

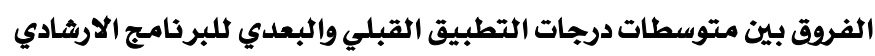

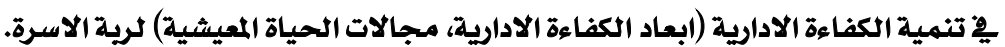

\begin{tabular}{|c|c|c|c|c|c|c|c|c|}
\hline اتجّاه & مستوى الدالة & $\begin{array}{c}\text { قيهة } \\
\text { (ت) } \\
\end{array}$ & الحرية & العينة & الالمعراف & الحتوسط & التطبيق & الادارية \\
\hline \multirow[b]{2}{*}{ البعلدي } & \multirow[b]{2}{*}{$\cdot, \cdot 1$} & \multirow[b]{2}{*}{ HI, \&\&V } & \multirow[b]{2}{*}{09} & \multirow[b]{2}{*}{7.} & $0 \cdot, 11 r$ & Frr, TAT & قبلي & \multirow{2}{*}{ الإدماسلي } \\
\hline & & & & & $1 \cdot, 0 . r$ & \&Tr, १७q & بعدي & \\
\hline
\end{tabular}

يتبين من الجدول السابق ان قيم "ت" كانت داله عند مستوى ا+., · لمقيـاس الكفـاءة الاداريـة

لربة الاسـرة ككل( ابعاد الكفاءة الادارية، مجالات الحيـاة المعيشية) لريـة الاسـرة وهـذا يـدل على وجـود

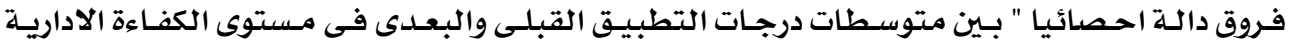
لــالح التطبيـق البعـدى وهـذا يـدل على تـاثير البرنـامـج المعـد باسـتخدام احسد تطبيقـات تكنولوجيـا

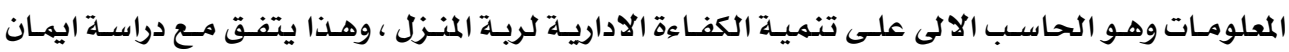

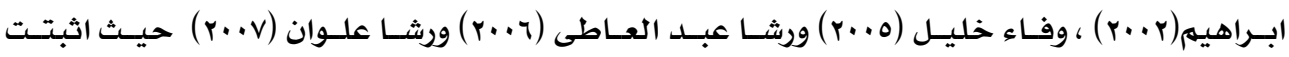




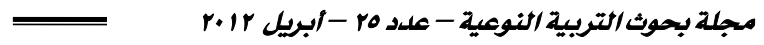

الدراسات فاعلية البر امـج المصممة باسـتخدام الحـاسب الالى فى تنـميـة القـدرات الاداريـة وتنميـة ادراك الزوجة لمواردها الاسرية و تنمية الكفاءة الادارية للمراة.

ولتحديد حجم تاثير المتغير المستقل استخدمت الباحثة مريع ايتا (n2 ) ويمكن حساب قيمسة مربع ايتا عن طريق المعادلة التالية

\begin{tabular}{|l|r|}
\hline $\mathrm{n}^{2}=$ & $\mathrm{T}^{2}$ \\
\cline { 2 - 2 } & $\mathbf{T}^{2}+\mathbf{d f}$ \\
\hline
\end{tabular}

حيث أن T2 هي مريـع قيمة (ت) df، درجـات الحريـة،وعن م2 يمكن التوصل الى نوعين مـن المعلومات:ا- يمكن تحويل قيمـة (n2) الى قيمة d وهى تعبر عن حجم التاثير فى التجربة.

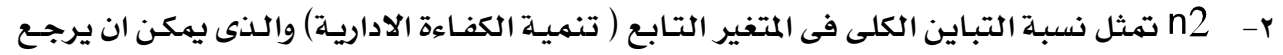
الى المتغير المستقل ( برنامج الكمبيوتر المصمم لتنمية الكفاءة الاداريـة ). ويتحدد حجم التاثير وما اذا كان كبيرا او صغيرا او متوسطا كالاتى :

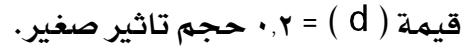

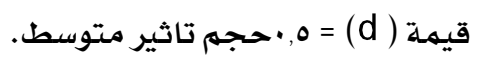

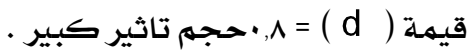

$$
\begin{aligned}
& \text { وبحساب حجم التاثير وجد ان n2 = }
\end{aligned}
$$

ويمكن تحويل قيمة ايتا n2 الى قيمة ( d ) المقابلة لها ومقدار حجم التاثير

$$
\begin{aligned}
& \frac{\sqrt[2]{n 2}}{\sqrt{1-n 2}} d==1,10 \text { باستخدام العلاقة } \\
& \text { إذن حجم التاثير كبير. }
\end{aligned}
$$

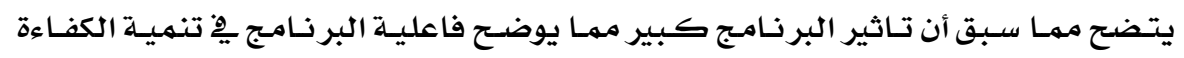
الادارية لرية الاسرة وبذلك يتحقق الفرض الثالث 
- - ابراهيم حامد الاسطل ، فريال يونس الخالدى (0. ․ ) : مهنة التعليم وادوار المعلم فى مدرسة المستقبل ، دار

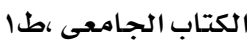

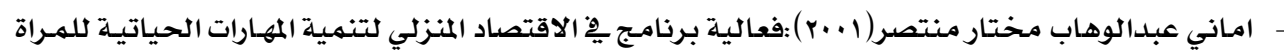

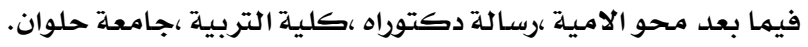

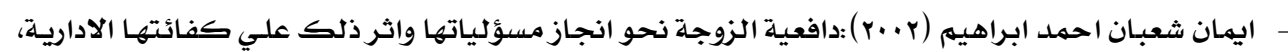
رسالة دكتوراه ،كلية الاقتصاد المنزلي ،جامعة حلوان.

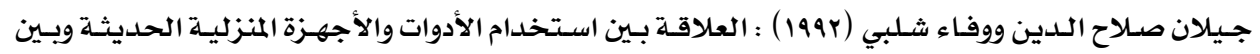

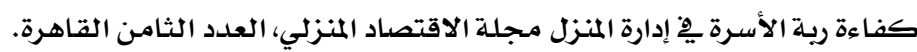

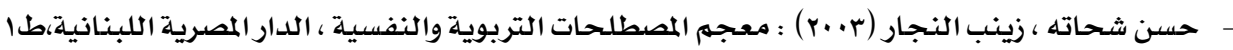

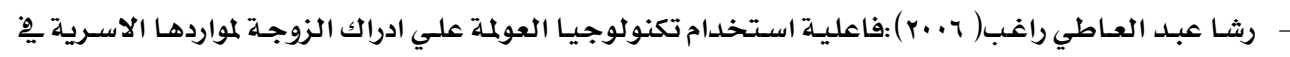

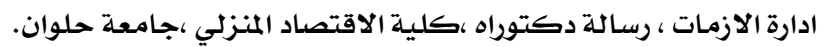

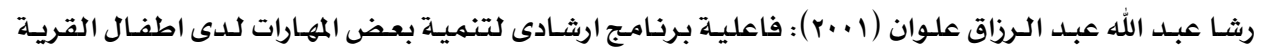

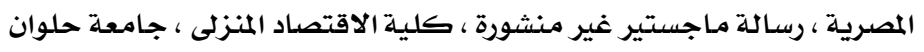

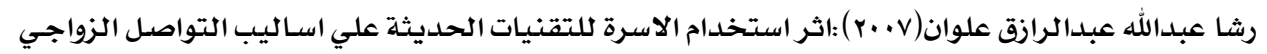

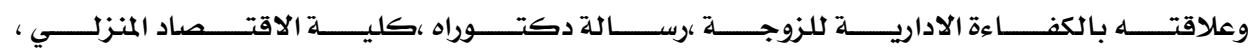
جامعة حلوان.

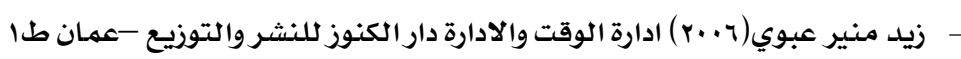

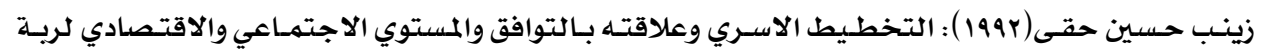

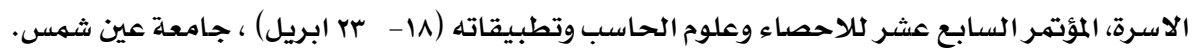

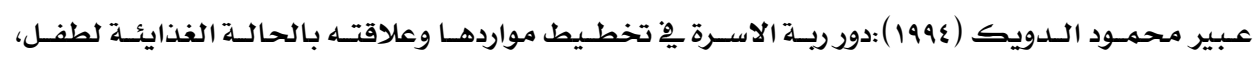
رسالثماجستير ، كلية الاقتصاد والمنزل ، جامعة المنوفية.

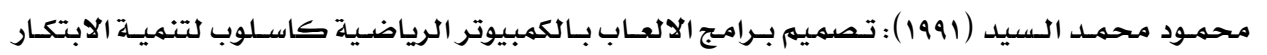

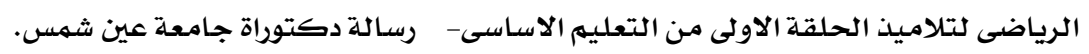

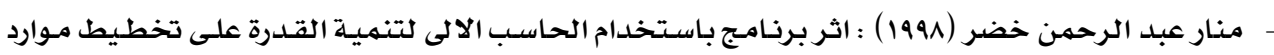

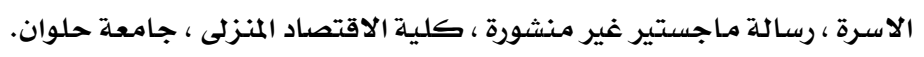

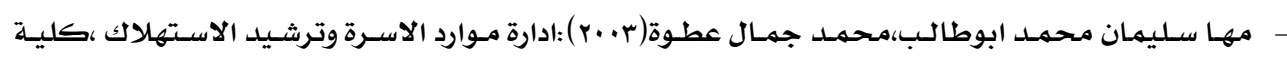
الزراعة ،جامعة الاسكندرية.

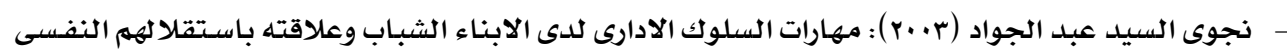

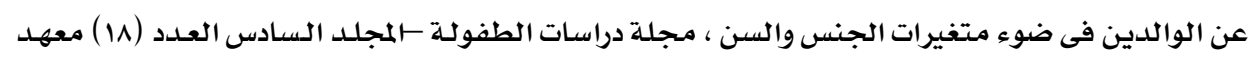

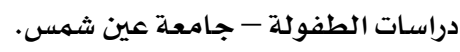




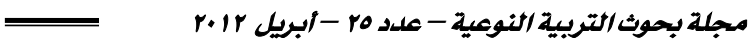

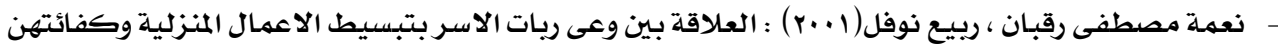

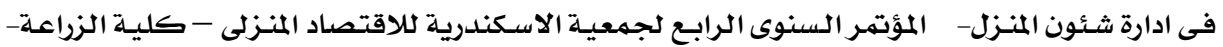

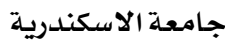

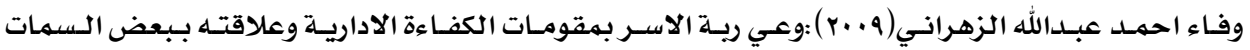

الشخصية ،رسالة ماجستير،كلية الفنون والتصميم الداخلي للبنات،جامعة أم القري.

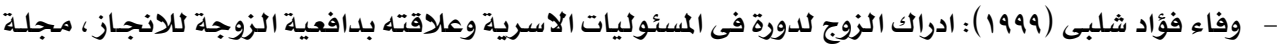

الاقتصساد المنزلى ، العدد الخامس عشر ، كلية الاقتصاد المنزلى ، جامعة حلوان.

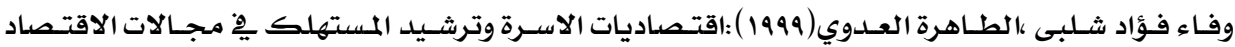

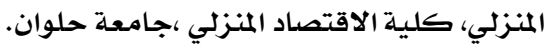

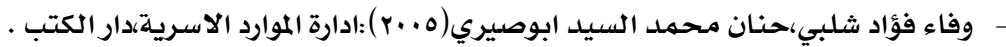

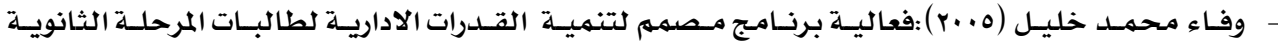

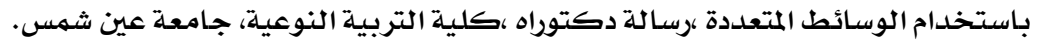

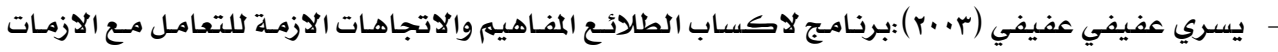

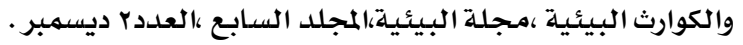

-Anne go(2000) : Internet and computer technology hazards: perspectives of family counseling. Journal of guidance and counseling. Vol.25, no,3p.309.

-Anne.W,bailey(1982) : the impact of comuter techolgy on the family. III ivois. Teacher of home economics, vol 25,no.4p199-202.

-Galbreah, Jeremy(1999).preparing the 21century Wrker: the link between computer- based technology and future skill sets. Educational Technology, nov, dec1422.

Godman, I, faith(1989): the relation ship between perception of family interaction and of television's role in the family- harrard university $482 p$

-Kearsley. G(1988) Educational Technology, Acritique, Educational Technology,38(2).

-Morgan, M. and signoriellie, N(1990) cultivation onaysis, new dirctions in media effects research, califoring sage publication, Inc, pp:(13.14) 